UNIVERSIDADE DA BEIRA INTERIOR

Ciências da Saúde

\title{
Experiências de pessoas idosas institucionalizadas sobre as Tecnologias de Informação e Comunicação (TIC) e perceção do estado de saúde
}

\author{
Joana Daniela Gomes da Cunha
}

Dissertação para obtenção do Grau de Mestre em

Medicina

(ciclo de estudos integrado)

Orientadora: Professora Doutora Rosa Marina Afonso

Coorientador: Professor Doutor José Martinez de Oliveira

Coorientador: Professor Doutor Paulo Duarte

Covilhã, abril de 2019 
Experiências de pessoas idosas institucionalizadas sobre as Tecnologias de Informação e Comunicação (TIC) e sua perceção do estado de saúde 
“Aqueles que passam por nós, não vão sós, não nos deixam sós.

Deixam um pouco de si, levam um pouco de nós."

Antoine de Saint-Exupéry 
Experiências de pessoas idosas institucionalizadas sobre as Tecnologias de Informação e Comunicação (TIC) e sua perceção do estado de saúde 


\section{Dedicatória}

A todos aqueles que sempre murmuraram "Vai dar tudo certo". A todos aqueles que me deram a mão e o abraço reconfortante. Aos de sempre. Aos que serão para sempre. Aos meus. 
Experiências de pessoas idosas institucionalizadas sobre as Tecnologias de Informação e Comunicação (TIC) e sua perceção do estado de saúde 


\section{Agradecimentos}

As palavras ficarão sempre aquém do meu sincero e colossal sentimento de agradecimento a todos aqueles que, direta ou indiretamente, contribuíram para a elaboração desta dissertação, contribuindo para a realização de uma importante etapa da minha formação académica. Ainda assim, não poderia deixar de manifestar o meu reconhecido apreço e gratidão.

À Professora Doutora Rosa Marina Afonso, minha orientadora, pela disponibilidade e amabilidade sempre demonstradas em orientar este projeto, pela colaboração na definição do tema e objeto de estudo, pela instrução sobre os passos a seguir, pela acessibilidade, pelo interesse sempre envolvido, por todo o carinho.

Ao Professor Doutor José Martinez de Oliveira, meu coorientador, pela iniciativa na definição do tema, pelos conselhos oportunos, pela acessibilidade e disponibilidade, pela serenidade e cordialidade sempre manifestadas.

Ao Professor Doutor Paulo Duarte, o meu sincero agradecimento pela coorientação neste projeto, por todo o profissionalismo e pela total disponibilidade e acessibilidade.

À Covilhã e à Faculdade de Ciências da Saúde, reconheço a oportunidade de crescimento, realização pessoal e formação científica.

Aos idosos, aos funcionários e responsáveis pelas instituições envolvidas no projeto, por toda a colaboração, generosidade e carinho envolvido.

Aos meus pais e à minha irmã, serei eternamente grata pelo amor incondicional, pela compreensão e constante encorajamento em continuar este percurso, pelo apoio incansável e inspiração diária, pela cumplicidade e pelo perdão sempre evidenciado por todas as ausências.

Aos meus amigos, pela presença, pela cumplicidade e carinho, pelo apoio constante, pelo incentivo diário, pelas palavras de força e esperança.

Aos meus pequenos, pela força que sempre me transmitiram, pelo aconchego do abraço sempre disponível, pela presença assídua, pelo carinho, pelo orgulho que têm em mim.

A todos,

0 meu eterno e sincero, 
Experiências de pessoas idosas institucionalizadas sobre as Tecnologias de Informação e Comunicação (TIC) e sua perceção do estado de saúde 


\section{Resumo}

Introdução: Os desenvolvimentos científico-técnicos e melhorias ao nível de saúde pública têm contribuído para o aumento da longevidade. Contudo, nem sempre o envelhecimento é acompanhado de qualidade de vida, sendo comum a baixa perceção da saúde. A institucionalização do idoso é uma resposta frequente à dependência, na ausência de soluções adequadas na comunidade e/ou família. A par desta realidade, as TIC têm vindo a instalar-se no dia-a-dia de todos, promovendo a comunicação e a construção de redes sociais, que não só minimizam as limitações impostas pela distância, como também podem desempenhar um papel essencial na integração/inclusão social das pessoas idosas. Este estudo pretende avaliar a perceção do estado de saúde e utilização das TIC por idosos institucionalizados, a possível relação entre estas dimensões, identificar quais as suas principais dificuldades e enumerar as características que esta população considera fundamentais num "equipamento ideal".

Materiais e Métodos: Trata-se de um estudo observacional, descritivo e transversal, desenvolvido com uma amostra de conveniência, com 114 idosos, com idades compreendidas entre os 66 e 95 anos $(M=84.42$; $D P=6.585)$. Para esta investigação, foi elaborado um questionário original que, depois de validado, foi distribuído e aplicado em 5 Instituições/Lares de Terceira Idade ou Estruturas Residenciais para Idosos da Beira Interior e de Viseu.

Resultados: Os resultados indicam que a maioria dos idosos avalia a sua saúde como "aceitável" (44 idosos, 38.6\%) e "boa" (38 idosos, 33.3\%). As TIC mais utilizadas são o telemóvel (78 idosos, $68.40 \%$ ) e o computador ( 20 idosos, $17.40 \%$ ), sendo que o uso do smartphone e do tablet é muito residual. Observa-se, com significância estatística, que aqueles que utilizam mais frequentemente o telemóvel apresentam pior perceção do estado de saúde ( $x^{2}=19.412$; $p=0.025)$. Constata-se que as principais atividades realizadas com as TIC são conversar com a família e amigos, verificando-se, com significância estatística, que os que referem ter medo na sua utilização, têm mais de 80 anos $\left(x^{2}=20.222 ; p=0.027\right)$. Depreende-se, ainda, que 70 idosos (61.4\%) referem sentir dificuldades na utilização dos equipamentos, sobretudo pela letra pequena, apontando o controlo de $\mathrm{voz}$ como a caraterística preferencial para o seu "equipamento ideal". Verifica-se, também, que 103 idosos consideram as TIC importantes e 62 têm interesse na sua utilização.

Conclusões: Este estudo alerta para a necessidade de desenvolver estratégias que permitam melhorar a perceção do estado de saúde dos idosos, bem como, fomentar a utilização das TIC no seu quotidiano, explorando os seus benefícios e asseverando a verdadeira inclusão social. Reconhece-se, também, a necessidade de realizar estudos, com amostras mais representativas. 


\section{Palavras-chave}

Envelhecimento; Perceção da Saúde; Tecnologias de Informação e Comunicação (TIC);

Internet; Inclusão Digital. 


\section{Abstract}

Introduction: The technological and scientific developments and the improvements in public healthcare has contributed to the increase in life expectancy. However, this is not always accompanied by life quality, and there is relatively low health perception. One common answer to the dependence of elderly people is their institutionalization, due to the lack of adequate solutions in the community and/or family. At the same time, the Information and Communications Technologies (ICT) are now a quotidian activity in everyone's life, promoting communication and the development of social networks, which mitigate the distance-imposed limitations and allow the social integration/inclusion of the elderly. This study aims to evaluate the health perception and the utilization of ICT by the institutionalized elderly population, exploring potential relationships between both, identify the mains difficulties, and listing the characteristics that this populations consider necessary in an "Ideal Digital Equipment".

Methods and Materials: This is an observational study, descriptive and cross-sectional, using a convenience sample of 114 people, aged between 66 and 95 years old $(A=84.42 ; S D=6.585)$. For this investigation, an original questionnaire was developed, that was later distributed and applied in 5 Institutions, devoted to the elderly in Beira Interior region and Viseu.

Results: The results indicate that the majority of the respondents evaluate their health as "acceptable" (44 people, 38.6\%) and "good" (38 people, 33.3\%). The most commonly used ICTs are the mobile phone (78 people, $68.40 \%$ ) and the computer (20 people, $17.40 \%$ ). The use of smartphones and tablets is residual. It was possible to identify, with statistical significance, that the mobile phone ones is the device more used and that the respondents have lower perception of their health status $\left(x^{2}=19.412 ; p=0.025\right)$. Furthermore, the main activities done with the ICTs are talking with family and friends. The findings show that, the ones who refer to be afraid of using ICTs are over 80 years old $\left(x^{2}=20.222 ; p=0.027\right)$. Seventy people $(61.4 \%)$ identify difficulties in using the equipment, especially due to the small letter size, pointing out the voice control feature as the preferred required characteristic for their "Ideal Digital Equipment". Finally, it was possible to find that 103 people consider ICTs important and 62 have display interest on their use.

Conclusion: This study warns for the need to develop strategies that allow the improvement of the health perception of elderly people as well as promoting the utilization of ICTs in their daily life, exploring its benefits to assure their true social inclusion. Further investigation are needed to support the current findings using a larger and more representative sample. 
Experiências de pessoas idosas institucionalizadas sobre as Tecnologias de Informação e Comunicação (TIC) e sua perceção do estado de saúde

\section{Keywords}

Aging; Health Perception; Information and Communications Technology (ICT); Internet;

Digital Inclusion. 


\section{Índice}

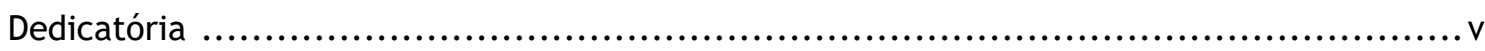

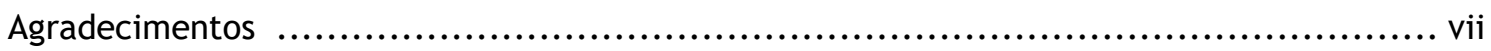

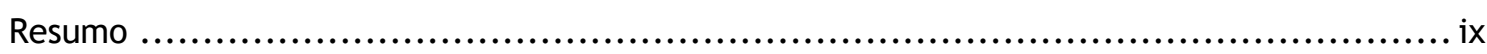

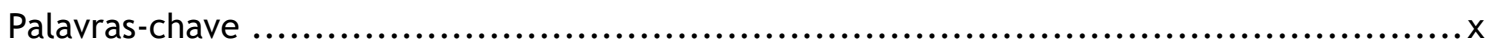

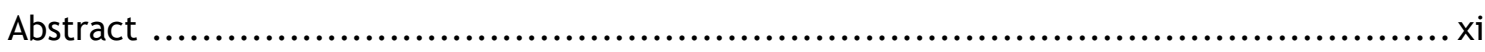

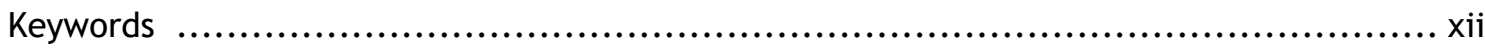

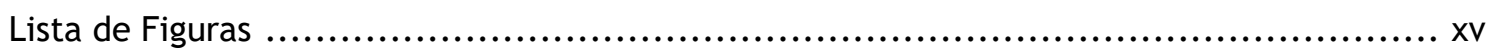

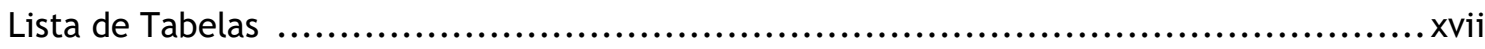

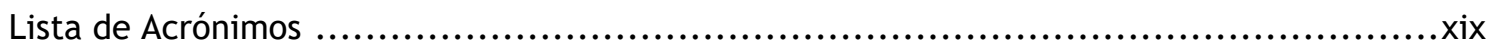

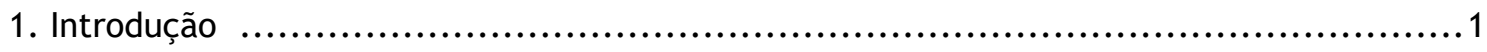

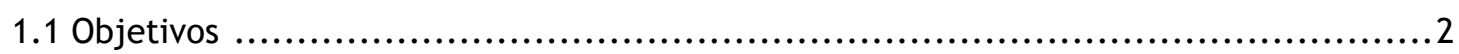

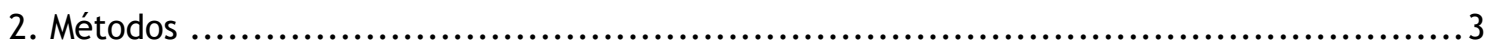

2.1 Descrição/Tipo de Estudo ..................................................................

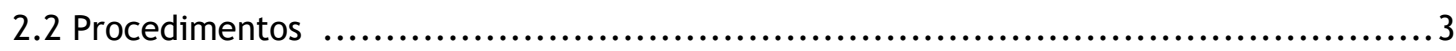

2.3 Amostra e Método de Recolha de Dados ........................................... 4

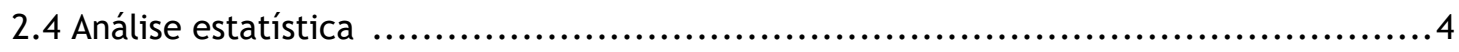

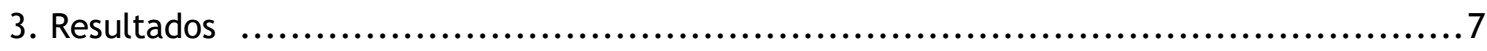

3.1 Caraterização da Amostra ......................................................

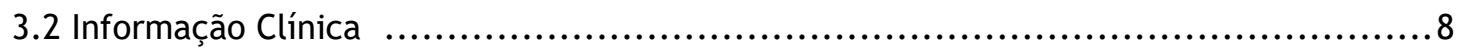

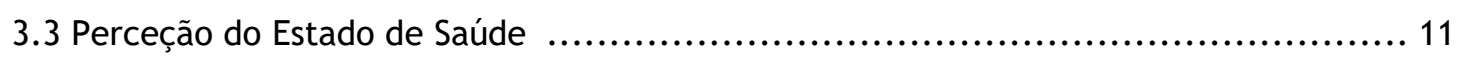

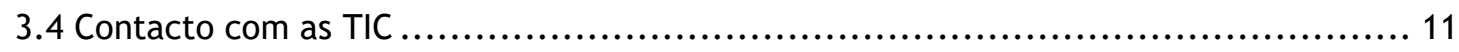

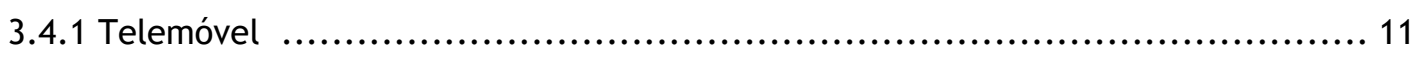


3.4.3 Tablet

3.5 Perceção do estado de saúde e grau de utilização das TIC .............................. 15

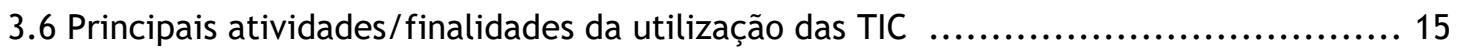

3.7 Primeira experiência com as TIC .................................................. 17

3.80 medo e as principais dificuldades na utilização das TIC ............................. 18

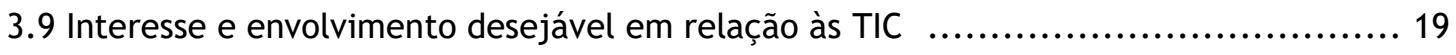

3.10 Caraterísticas de um "equipamento ideal" ....................................... 20

3.11 Medo da Internet ................................................................... 20

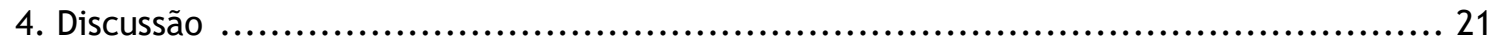

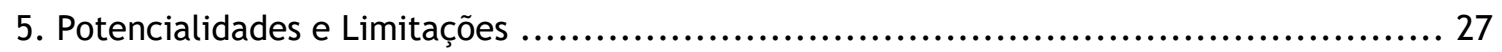

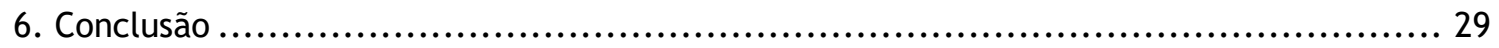

Referências Bibliográficas ................................................................... 31

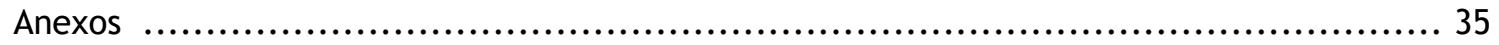

Al Questionário ....................................................................... 35

A II - Parecer da Comissão de Ética da Faculdade de Ciências da Saúde .................... 42

A III - Email direcionado às Instituições ...................................................... 43 


\section{Lista de Figuras}

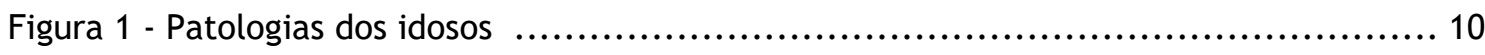

Figura 2 - Classes de fármacos realizadas pelos idosos ..................................... 10

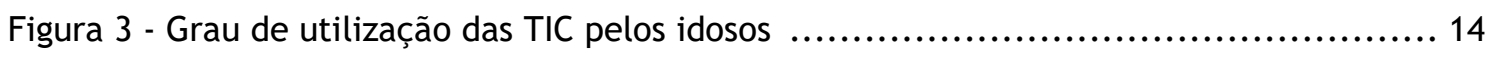

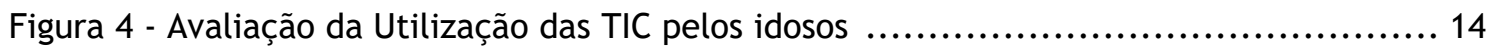

Figura 5 - Principais Dificuldades mencionadas na utilização das TIC ...................... 18

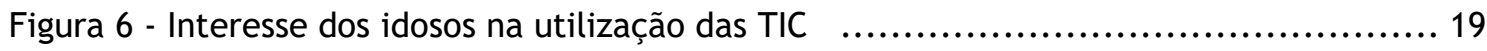

Figura 7 - Caraterísticas de um equipamento "ideal" ..................................... 20 
Experiências de pessoas idosas institucionalizadas sobre as Tecnologias de Informação e Comunicação (TIC) e sua perceção do estado de saúde 


\section{Lista de Tabelas}

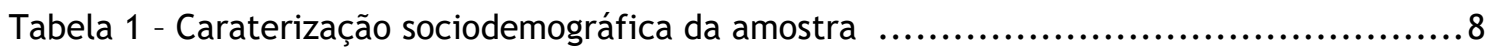

Tabela 2 - Perceção dos Idosos sobre o seu Estado de Saúde................................. 11

Tabela 3 - Relação entre a perceção do estado de saúde e a utilização do telemóvel ......... 15

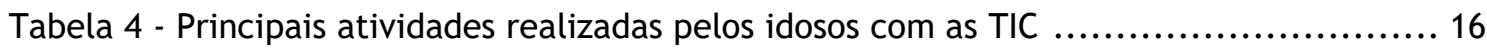


Experiências de pessoas idosas institucionalizadas sobre as Tecnologias de Informação e Comunicação (TIC) e sua perceção do estado de saúde 


\section{Lista de Acrónimos}

TIC

Tlm

$\mathrm{SPh}$

Tbt

PC

SPSS

DP

INE

OCDE
Tecnologias de Informação e Comunicação

Telemóvel

Smartphone

Tablet

Computador

Software Package for Social Sciences

Desvio-padrão

Instituto Nacional de Estatística

Organização para a Cooperação e Desenvolvimento Económico 
Experiências de pessoas idosas institucionalizadas sobre as Tecnologias de Informação e Comunicação (TIC) e sua perceção do estado de saúde 


\section{Introdução}

O envelhecimento da população é um dos maiores desafios para a sociedade contemporânea. Fruto do aumento da esperança média de vida, constata-se que o número de pessoas idosas tende a aumentar, mundialmente $(1,2)$. Trata-se de um processo inevitável, inerente a todos, embora apresente grande variabilidade interindividual, de acordo com as características genéticas e o modo de vida de cada um(3).

À medida que as incapacidades físicas, cognitivas e psicológicas do idoso se instalam e, inversamente, a sua rede informal (cônjuge, filhos, amigos e vizinhos) diminui, surge, frequentemente, a necessidade de recorrer à rede formal (organizações estatais ou privadas de apoio aos idosos)(4). Ao idoso, homem ou mulher com idade igual ou superior a 65 anos, a institucionalização exige a adaptação a um ambiente coletivo com normas que nem sempre estão de acordo com a sua personalidade, o que poderá ter implicações no seu bem-estar, independência, privacidade e intimidade $(5,6)$. Os idosos institucionalizados exigem maior suporte, apresentando, frequentemente, maior morbilidade física e mental(5).

Paralelamente ao envelhecimento da população, assiste-se à acelerada instalação e proliferação das TIC no quotidiano(7). Entende-se por TIC qualquer recurso tecnológico que permite transmitir uma informação, incluindo o hardware e todo software necessário ao seu funcionamento(7).

A geração mais nova estabelece uma relação de intimidade e identidade com os "artefactos" tecnológicos, absorvendo facilmente as mudanças(8). São considerados Nativos Digitais, “falantes nativos” da linguagem digital, graças à sua omnipresença (9). No entanto, para a geração mais velha, anteriores ao universo digital, há uma menor assimilação, sendo denominados Imigrantes Digitais $(8,9)$. A primazia atribuída às TIC pode ser negligenciada por aqueles que não tem acesso à tecnologia, ficando excluídos da movimentação social e confluência comunicacional, sendo os idosos um dos grupos potencialmente infoexcluídos(7). Frequentemente, são eles próprios que se colocam à margem por medo, falta de conhecimentos, inadequação dos equipamentos(3).

Todavia, as tecnologias podem permitir a inclusão do idoso, possibilitando o acesso a múltiplos serviços e informações(3). A comunicação virtual permite fortalecer laços intergeracionais, cada vez mais enfraquecidos pelo desmembramento familiar e as exigências profissionais(7). A inclusão digital estimula a autonomia, previne o declínio cognitivo, reduz o sentimento de solidão e sintomas depressivos, garante maior abrangência da assistência em saúde (telemonitorização - deteção de quedas com sistema de alerta ao cuidador, monitorização da toma de medicação e atividade física - cada vez mais utilizada), com diminuição do impacto das doenças crónicas(10-12). Idosos que utilizam as TIC evidenciam maior sensação de bemestar e segurança, melhor qualidade de vida e capacitação nas relações interpessoais(13-15). 
As TIC podem, assim, ter um forte impacto na perceção do estado de saúde, considerada um preditor de saúde objetiva, que relaciona as variáveis sociodemográficas, doenças crónicas, grau de incapacidade funcional e depressão, sendo útil na previsão do declínio funcional e das necessidades de cuidados de saúde $(16,17)$. Nos idosos, a perceção do estado de saúde é muito influenciada pela forma como comparam a sua saúde com a de outros idosos, da mesma idade e sob condições de vida similares (comparações sociais) e com o seu estado de saúde de outros períodos de vida (comparações temporais)(18). Apesar do estado de saúde e da auto-perceção em saúde deteriorarem com o tempo, são conceitos diferentes, dependentes de vários fatores(18).

Em 2007, a Comissão Europeia desenvolveu um plano "Envelhecer bem na sociedade da informação" com o objetivo de incrementar a inclusão das TIC na prestação de serviços aos idosos, asseverando uma velhice mais segura e autónoma(7). Em Portugal, existem diversas iniciativas que difundem a utilização das TIC pelos mais velhos, das quais as Universidades da Terceira Idade são exemplo. Através de cursos de informática, vão capacitando os idosos a manusear as novas tecnologias, assegurando uma maior participação crítica sob a vida sociocomunitária(3). Conquanto, é fulcral planificar metodologias direcionadas para os idosos, atendendo ao seu processo cognitivo, recursos mais limitados e as restrições sensoriais próprias do envelhecimento, caso contrário o uso das TIC pode gerar conflitos $(7,16)$.

\subsection{Objetivos}

Os objetivos deste estudo são:

1. Avaliar a perceção do estado de saúde.

2. Avaliar o grau de utilização e experiências em relação às TIC de uma população idosa institucionalizada;

3. Averiguar quais as principais dificuldades e receios no uso destes equipamentos;

4. Identificar as características que esta população considera fundamentais num "equipamento ideal".

5. Analisar a relação entre a utilização das TIC e a perceção da saúde. 


\section{Métodos}

\subsection{Descrição/Tipo de Estudo}

Trata-se de um estudo observacional, descritivo e transversal/cross-sectional.

É considerado observacional, visto que, o investigador descreve, não influenciando os participantes, nem modificando os dados. Enquadra-se na categoria de estudo descritivo pois apresenta de forma organizada informações/experiências dos indivíduos da amostra. Considerase, ainda, transversal/cross-sectional uma vez que se trata da observação de uma amostra num determinado momento temporal.

\subsection{Procedimentos}

Primeiramente, procedeu-se a uma revisão da literatura, nomeadamente, através da realização de pesquisa na PubMed, tendo sido usados como termos de pesquisa: Elderly, Aged, Old people vs. Computers, Communication technologies, Communications skills, iPads, Cell phones. Foram ainda consultadas outras referências bibliográficas (livros, artigos científicos, entre outras) sobre a utilização das TIC por idosos, a perceção do estado de saúde e a relação entre estas dimensões.

Posteriormente, analisaram-se alguns questionários aplicados em estudos nacionais e internacionais, como base para a construção de um questionário original (anexo 1), dividido em 5 partes, abordando as variáveis em estudo.

A primeira parte pretende avaliar qual a perceção do estado de saúde que os idosos apresentam.

A segunda parte tem como objetivo identificar qual o contacto e experiências que os idosos têm com os diferentes equipamentos tecnológicos [Telemóvel (Tlm), Smartphone (SPh), Tablet (Tlt) e Computador (PC)], quais as finalidades com que usam as TIC e quais as suas principais dificuldades.

A terceira parte visa avaliar o interesse dos idosos na utilização das TIC e quais as caraterísticas que consideram fundamentais para a construção de um equipamento "ideal".

Por fim, a quarta e quinta parte do questionário incluem o levantamento de dados pessoais e sociodemográficos, bem como, a informação clínica (patologias e medicação respetiva) do participante.

O estudo foi submetido à Comissão de Ética da Universidade da Beira Interior, tendo sido aprovado pela mesma na reunião do dia 10 de julho de 2018 (anexo 2). 
Para além do consentimento informado, assegurou-se o anonimato de todos os participantes da amostra, bem como, a confidencialidade dos dados recolhidos. Assim, foram cumpridas todas as normas vigentes no âmbito dos trabalhos de investigação, segundo os princípios da Declaração de Helsínquia.

De seguida, estabeleceu-se contacto, via e-mail, com algumas Instituições/Lares da Terceira Idade ou Estruturas Residenciais para pessoas idosas da Beira Interior e de Viseu para se averiguar a disponibilidade para participação no estudo (anexo 3). Após terem sido obtidas algumas respostas positivas procedeu-se ao planeamento das deslocações às instituições para aplicação dos questionários.

Posteriormente à recolha de dados procedeu-se à sua inserção numa base de dados (anonimizados) e à sua análise estatística, para posterior discussão dos resultados e conclusão.

\subsection{Amostra e Método de Recolha de Dados}

Participaram no estudo, utentes das seguintes instituições:

- Lar de Nossa Senhora de Fátima da Santa Casa da Misericórdia do Fundão

- Lar de São José - Covilhã

- Mutualista Covilhanense

- Residência Rainha Leonor - Santa Casa da Misericórdia de Viseu

- Centro Paroquial de Nelas

A aplicação dos questionários teve início no dia 12 de Novembro de 2018 e foi concluída no dia 29 de Janeiro de 2019.

Definiram-se como critérios de inclusão no estudo:

- Ter idade igual ou superior a 65 anos;

- Encontrar-se institucionalizado em Lar/Residência;

- Não apresentar défices cognitivos que impossibilitassem a participação no estudo.

Foram excluídos deste estudo os idosos que apenas frequentassem o centro de dia ou que apresentassem patologia do foro neurológico que comprometesse a validade das respostas.

\subsection{Análise estatística}

Para o registo de dados, recolhidos através de questionário, usou-se o Microsoft Office Excel 2013® e para a análise estatística dos dados recorreu-se ao Software Package for Social Sciences (SPSS $\circledast$ ), versão 25 para a Microsoft Windows $®$. 
Procedeu-se à análise descritiva dos dados sociodemográficos para caraterização da amostra, sendo construídas tabelas de frequências e gráficos ilustrativos da distribuição de respostas.

A utilização do teste do qui-quadrado permite, perante duas variáveis nominais ou uma variável nominal e outra ordinal, testar a associação entre pares de variáveis, admitindo-se duas hipóteses(19):

- H0: As duas variáveis são independentes, ou seja, não existe relação entre as categorias de uma variável e as categorias da outra;

- H1: As duas variáveis apresentam uma relação entre si, ou seja, existe relação entre as categorias de uma variável e as categorias da outra;

Quando o valor da probabilidade associada ao teste do qui-quadrado $(p)$ for inferior a $5 \%(0.05)$, rejeita-se a hipótese nula (H0), concluindo-se que não é possível excluir a hipótese das duas variáveis estarem relacionadas. Quando o valor da probabilidade associada ao teste do quiquadrado $(p)$ for superior ao valor de referência de $5 \%(0,05)$, não se pode rejeitar a hipótese nula, ou seja, conclui-se que as variáveis não estão relacionadas(19). 
Experiências de pessoas idosas institucionalizadas sobre as Tecnologias de Informação e Comunicação (TIC) e sua perceção do estado de saúde 


\section{Resultados}

\subsection{Caraterização da Amostra}

Relativamente às caraterísticas sociodemográficas da amostra, verifica-se que $79(69.3 \%)$ idosos são do género feminino e 35 (30.7\%) são do género masculino.

Em relação à distribuição da amostra por idades, a idade mínima é de 66 anos e a máxima de 95 anos, sendo a média 84.42 ( $D P=6.585)$. Verifica-se, ainda, que $63(55.3 \%)$ idosos que compõem a amostra têm idades compreendidas entre os 80 e 89 anos, mais especificamente, 34 idosos (29.8\%) têm entre 85 e 89 anos, sendo este o intervalo de idades mais representativo da amostra.

Quanto ao meio de origem, $72(63.2 \%)$ idosos cresceram num meio rural e $42(36.8 \%)$ cresceram num meio urbano.

No que diz respeito à escolaridade, 53 idosos (46.5\%) referem ter a $4^{\mathrm{a}}$ classe, e 27 (23.7\%) referem ter uma licenciatura. As profissões desempenhadas por cada um são diversas, sendo as mais mencionadas: doméstica (27.2\%), professor(a) (14.9\%) e agricultor(a) (11.4\%) (Tabela 1).

Tendo em conta o agregado familiar, 80 idosos (70.2\%) referem ter filhos e, destes, 63, ou seja, $55.3 \%$ afirmam ter netos. Da totalidade da amostra $29.8 \%$ indica não ter descendência. Além disso, 51 idosos (44.7\%) indicam não ter irmãos. Cerca de 23 idosos $(20.2 \%)$ refere outros elementos do agregado familiar, como amigos ( $0.9 \%)$, bisnetos $(5.3 \%)$, sobrinhos $(4.4 \%)$, entre outros.

Em relação ao local onde se encontra o agregado familiar as respostas são diversas: 41 idosos (36\%) responderam Viseu, 14 (12.3\%) Lisboa, 13 (11.4\%) Covilhã, 5 (4.4\%) França, 13 (11.4\%) dizem estar "perto". Os restantes referem outros locais como Porto (3.5\%), Coimbra (1.8\%), entre outros (Tabela 1). 
Experiências de pessoas idosas institucionalizadas sobre as Tecnologias de Informação e Comunicação (TIC) e sua perceção do estado de saúde

Tabela 1 - Caraterização sociodemográfica da amostra $(N=114)$

\begin{tabular}{|c|c|c|c|}
\hline Variável & & Frequência & Percentagem \\
\hline \multirow[t]{2}{*}{ Género } & Feminino & 79 & $69.3 \%$ \\
\hline & Masculino & 35 & $30.7 \%$ \\
\hline \multirow[t]{4}{*}{ Idade } & $<70$ anos & 3 & $2.6 \%$ \\
\hline & 70-79 anos & 21 & $18.4 \%$ \\
\hline & 80-89 anos & 63 & $55.3 \%$ \\
\hline & $\geq 90$ anos & 27 & $23.7 \%$ \\
\hline \multirow[t]{2}{*}{ Meio } & Rural & 72 & $63.2 \%$ \\
\hline & Urbano & 42 & $36.8 \%$ \\
\hline \multirow[t]{2}{*}{ Escolaridade } & $4^{\mathrm{a}}$ classe & 53 & $46.5 \%$ \\
\hline & Licenciatura & 27 & $23.7 \%$ \\
\hline \multirow[t]{3}{*}{ Profissão } & Doméstica & 31 & $27.2 \%$ \\
\hline & Professor(a) & 17 & $14.9 \%$ \\
\hline & Agricultor & 13 & $11.4 \%$ \\
\hline \multirow[t]{3}{*}{ Agregado Familiar } & Filhos & 80 & $70.2 \%$ \\
\hline & Netos & 63 & $55.3 \%$ \\
\hline & Irmãos & 63 & $55.3 \%$ \\
\hline Localização do & Viseu & 41 & 36 \\
\hline \multirow[t]{3}{*}{ Agregado Familiar } & Lisboa & 14 & $12.3 \%$ \\
\hline & Covilhã & 13 & $11.4 \%$ \\
\hline & “Perto” & 13 & $11.4 \%$ \\
\hline
\end{tabular}

\subsection{Informação Clínica}

A informação clínica foi recolhida através de questões aos idosos sobre as suas principais patologias e medicação e através da consulta do seu processo clínico (Figura 1 e 2).

Posteriormente, de forma a garantir uma melhor exposição da informação, os dados obtidos foram organizados em diferentes grupos, nomeadamente:

- Problemas osteoarticulares (osteoporose, artroses, fraturas, dores articulares);

- Doenças cardiovasculares (enfarte do miocárdio, diabetes mellitus, hipertensão arterial, dislipidémia, obesidade, angina, arritmias);

- Problemas gastrointestinais (gastrite, úlcera, doença inflamatória intestinal, cirrose, hepatite);

- Problemas hematológicos (anemia, trombose);

- Problemas respiratórios (asma, doença pulmonar obstrutiva crónica, pneumonia, pneumonites); 
Experiências de pessoas idosas institucionalizadas sobre as Tecnologias de Informação e Comunicação (TIC) e sua perceção do estado de saúde

- Distúrbios endocrinológicos (disfunção tiroideia);

- Distúrbios neurológicos (cefaleias, traumatismo, acidente vascular cerebral, doença de Parkinson, depressão);

- Distúrbios neoplásicos;

- Distúrbios urológicos (hiperplasia benigna da próstata e outros distúrbios genitourinários).

A medicação foi também organizada em grupos. 


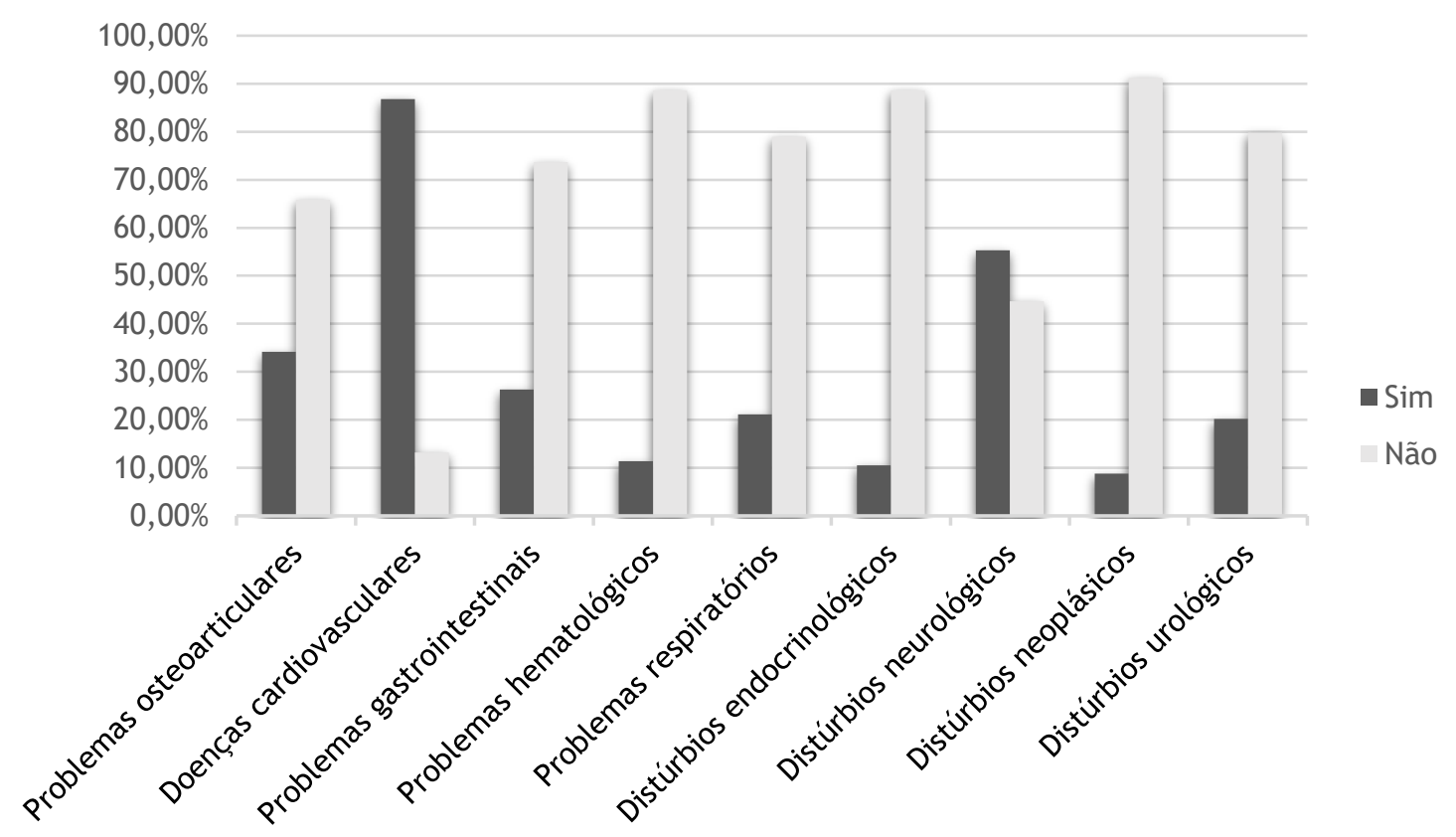

Figura 1 - Patologias dos idosos $(N=114)$

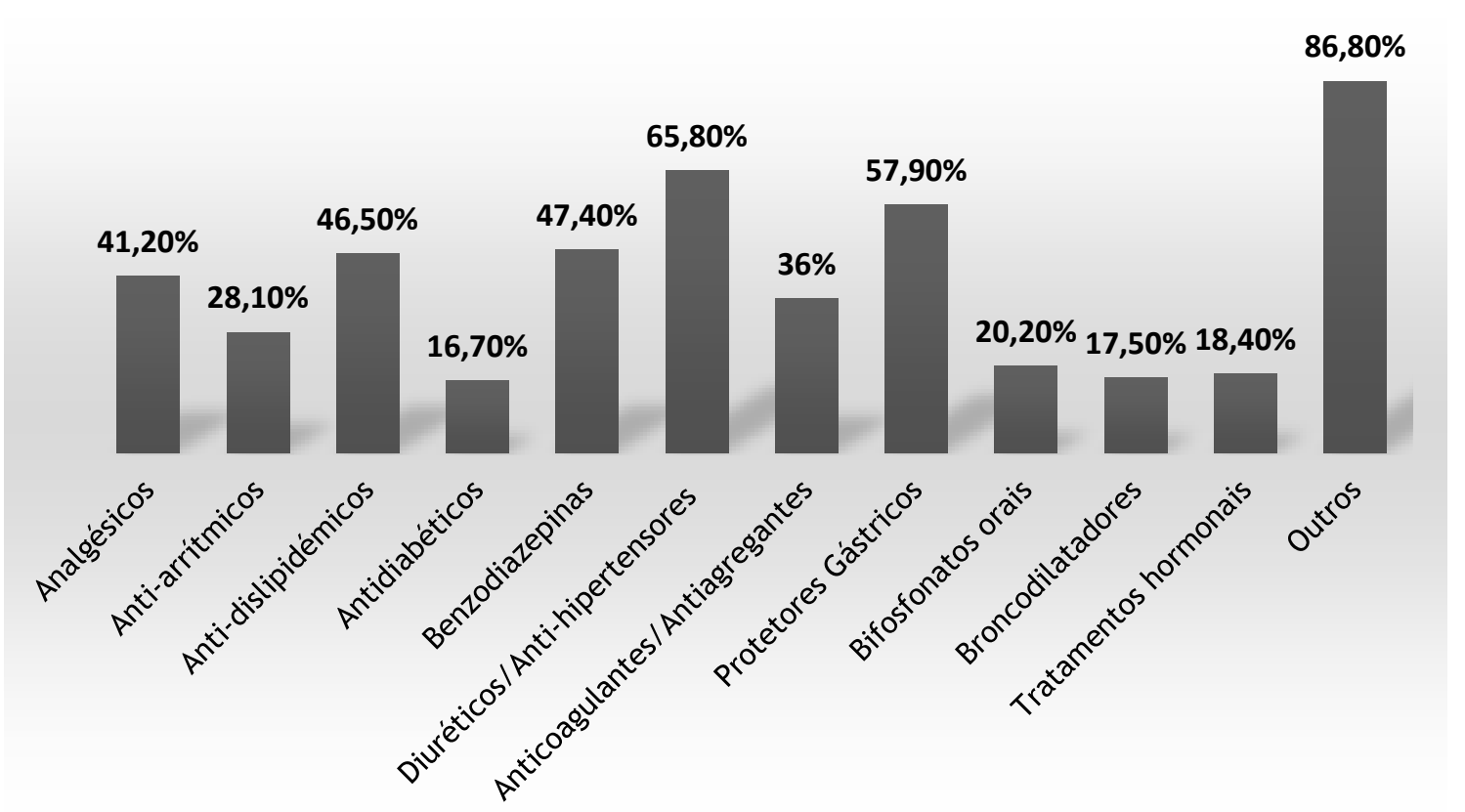

Figura 2 - Classes de fármacos realizadas pelos idosos $(N=114)$ 


\subsection{Perceção do Estado de Saúde}

Quanto à perceção do estado de saúde, as respostas mencionadas pelos idosos foram as evidenciadas na Tabela 2, sendo que as resposta mais assinaladas foram "aceitável" (44 idosos, $38.6 \%$ ) e "boa" (38 idosos, 33.3\%).

Tabela 2 - Perceção dos Idosos sobre o seu Estado de Saúde

\begin{tabular}{|c|c|c|c|c|c|}
\hline & Má & Aceitável & Boa & Muito boa & Excelente \\
\hline $\begin{array}{c}\text { Auto-avaliação do estado } \\
\text { geral de saúde }\end{array}$ & $24(21.1 \%)$ & $44(38.6 \%)$ & $38(33.3 \%)$ & $7(6.1 \%)$ & $1(0.9 \%)$ \\
\hline Auto-avaliação da Visão & $25(21.9 \%)$ & $32(28.1 \%)$ & 39 (34.2\%) & $18(15.8 \%)$ & $0(0.0 \%)$ \\
\hline Auto-avaliação da audição & $22(19.3 \%)$ & $30(26.3 \%)$ & $41(36.0 \%)$ & $15(13.2 \%)$ & $6(5.3 \%)$ \\
\hline $\begin{array}{l}\text { Auto-avaliação da } \\
\text { Coordenação motora }\end{array}$ & $7(6.1 \%)$ & $21(18.4 \%)$ & $39(34.2 \%)$ & $29(25.4 \%)$ & $18(15.8 \%)$ \\
\hline Auto-avaliação da memória & $8(7.0 \%)$ & $32(28.1 \%)$ & $51(44.7 \%)$ & $18(15.8 \%)$ & 5 (4.4\%) \\
\hline $\begin{array}{c}\text { Auto-avaliação da } \\
\text { autonomia }\end{array}$ & $2(1.8 \%)$ & 30 (26.3\%) & 38 (33.3\%) & $25(21.9 \%)$ & $19(16.7 \%)$ \\
\hline
\end{tabular}

Salientar ainda que, para um nível de significância de $5 \%$, os resultados sugerem que não existe uma associação estatisticamente significativa entre a perceção do estado geral de saúde e os dados sociodemográficos, nomeadamente, a idade, o género e o meio $\left(x^{2}=8.335 ; p=0.989\right)$.

\subsection{Contacto com as TIC}

\subsubsection{Telemóvel}

Em relação ao telemóvel, verifica-se que 112 (98.2\%) idosos sabem o que é e 92 (80.7\%) referem que já utilizaram este equipamento (Figura 3 ).

Destes, 14 idosos (12.3\%) afirmam que já não o utilizam. Dois deles (1.8\%) justificam esse facto pelas limitações físicas impostas pela idade. Três idosos (2.6\%) referem a sua substituição por outro equipamento (nomeadamente o smartphone) e 4 idosos (3.6\%) admitem ter dificuldades de acesso por questões económicas. Um idoso $(0.9 \%)$ refere não sentir necessidade de usar este equipamento e outro idoso $(0.9 \%)$ confessa que as dificuldades no manuseamento do equipamento levaram ao seu abandono.

Daqueles que continuam a usar o telemóvel, 6 idosos (5.3\%) fazem-no raramente, 19 (16.7\%) ocasionalmente, $33(28.9 \%)$ frequentemente e 20 idosos (17.5\%) referem fazê-lo sempre. 
Quanto à avaliação da sua utilização, verifica-se que um idoso $(0.9 \%)$ a classifica como má, 14 (12.3\%) como aceitável, $33(28.9 \%)$ como boa, 32 (28.1\%) como muito boa e, ainda, 12 idosos (10.1\%) classificam-na como excelente (Figura 4).

Os resultados sugerem que, para um nível de significância de $5 \%$, existe uma associação estatisticamente significativa entre a idade e utilização do telemóvel $\left(x^{2}=32.202 ; p=0.041\right)$. Ao consultar a tabela de frequências, verifica-se que aqueles que utilizam mais frequentemente $o$ telemóvel estão em faixas etárias mais elevadas, nomeadamente, acima de 80 anos. Os resultados indicam, também, para um nível de significância de 5\%, uma associação estatisticamente significativa entre a idade e a forma como os idosos avaliam a sua experiência com o telemóvel $\left(x^{2}=34.287 ; p=0.024\right)$, observando-se que aqueles que a classificam como "muito boa" $\mathrm{e}$ "excelente" são sobretudo idosos com mais de 80 anos. Os resultados não indicam uma relação entre o grau de utilização do telemóvel com outras variáveis, tais como o género $\left(x^{2}=3.381\right.$; $p=0.496)$, e o meio onde os idosos cresceram ( $\left.x^{2}=5.510 ; p=0.239\right)$.

\subsubsection{Smartphone}

Da totalidade da amostra, 64 idosos indicam desconhecer o que é um smartphone contra 49 (43\%) que afirma saber o que é (Figura 3).

Destaque-se que 6 idosos (5.3\%) referem ter usado um, sendo que destes, um fá-lo apenas ocasionalmente $(0.9 \%), 3$ usam-no frequentemente (2.6\%), 1 deles utiliza-o sempre $(0.9 \%)$ e 1 dos idosos já não usa (0.9\%). Em termos de avaliação desta experiência, 1 idoso refere ser aceitável (0.9\%), 2 idosos classificam-na como boa (1.8\%), 2 como muito boa (1.8\%) e 1 como excelente (0.9\%) (Figura 4).

Salientar que, os resultados não sugerem, com significância estatística, qualquer associação entre o grau de utilização do smartphone e a idade $\left(x^{2}=12.667 ; p=0.178\right)$, género $\left(x^{2}=3.000 ; p=0.392\right)$, e meio $\left(x^{2}=6.000 ; p=0.112\right)$.

\subsubsection{Tablet}

A análise realizada ao uso do tablet revelou que 36 idosos (31.6\%) conhecem o equipamento e 9 (7.9\%) referem que já utilizaram um. É interessante notar que, atualmente, 5 idosos continuam a utilizá-lo (2.6\% raramente, $0.9 \%$ frequentemente, $0.9 \%$ sempre) (Figura 3$)$.

Quanto à experiência de utilização do tablet, 4 idosos (3.5\%) caraterizam-na como aceitável, 1 $(0.9 \%)$ como boa e os restantes como muito boa (Figura 4$)$.

Para um nível de significância de $5 \%$, os resultados indicam uma relação estatisticamente significativa entre a idade e o grau de conhecimento do tablet $\left(x^{2}=14.640 ; p=0.012\right)$, sendo que dos 78 idosos que desconhecem este equipamento, 57 tem mais de 80 anos. Ainda, para um nível 
de significância de 5\%, os resultados parecem indicar uma associação estatisticamente significativa entre a escolaridade e o grau de conhecimento do tablet ( $\left.x^{2}=17.195 ; p=0.042\right)$, verificando-se que

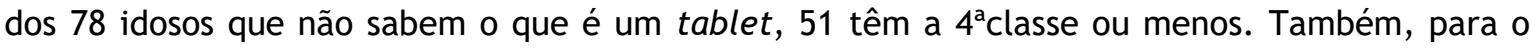
mesmo nível de significância, os dados sugerem uma relação estatisticamente significativa entre o meio e o grau de conhecimento do tablet $\left(x^{2}=3.915 ; p=0.048\right)$, pelo que, após análise da tabela de frequências se perceciona que a maioria dos idosos que desconhece este equipamento cresceu num meio rural.

\subsubsection{Computador}

No que diz respeito ao computador, 105 idosos (92.1\%) afirmam que sabem o que é e 29 idosos (25.4\%) revelam que já o utilizaram (Figura 3).

Daqueles que já contataram com o computador, verifica-se que 8 (7\%) continuam a fazê-lo, embora raramente, 6 (5.3\%) fazem-no ocasionalmente, 1 (0.9\%) frequentemente e $5(4.4 \%)$ continuam a utilizá-lo sempre.

Cerca de 13 idosos (11.4\%) classificam a experiência de utilização como muito boa, 1 (0.9\%) como má, 3 (2.6\%) como aceitável, 9 (7.9\%) como boa e 3 (2.6\%) como excelente (Figura 4).

Quanto às razões enumeradas para a não utilização deste equipamento, 5 idosos (4.4\%) referem ter dificuldades de acesso ao equipamento e 2 idosos (1.8\%) referem que não gostam de usar o computador. Ainda, 2 idosos (1.8\%) afirmam não ter necessidade em utilizá-lo e 1 idoso diz apresentam limitações físicas que impedem a sua utilização.

Os resultados indicam uma associação estatisticamente significativa entre o meio e a utilização do computador ( $x^{2}=10.637 ; p=0.001$ ), para um nível de significância de $5 \%$. Efetivamente, observase que dos 29 idosos que referiram já ter utilizado este equipamento, 18 são do meio urbano e dos 85 idosos que referiram nunca o ter utilizado, 61 são do meio rural. Para além disso, verifica-se que, para o mesmo nível de significância, existe uma relação estatisticamente significativa entre o género e o conhecimento sobre o que é o computador ( $\left.x^{2}=4.329 ; p=0.037\right)$, constata-se que dos 105 idosos que afirmam saber o que é um computador, 70 são do género feminino. Finalmente, os resultados sugerem, para um nível de significância de 5\%, uma associação estatisticamente significativa ( $x^{2}=24.441 ; p=0.003$ ) entre o nível de escolaridade e a utilização do computador, pelo que, dos 29 idosos que já utilizaram esta tecnologia, 14 têm uma licenciatura e dos 79 que nunca o utilizaram, 56 têm a $4^{\mathrm{a}}$ classe ou menos. 


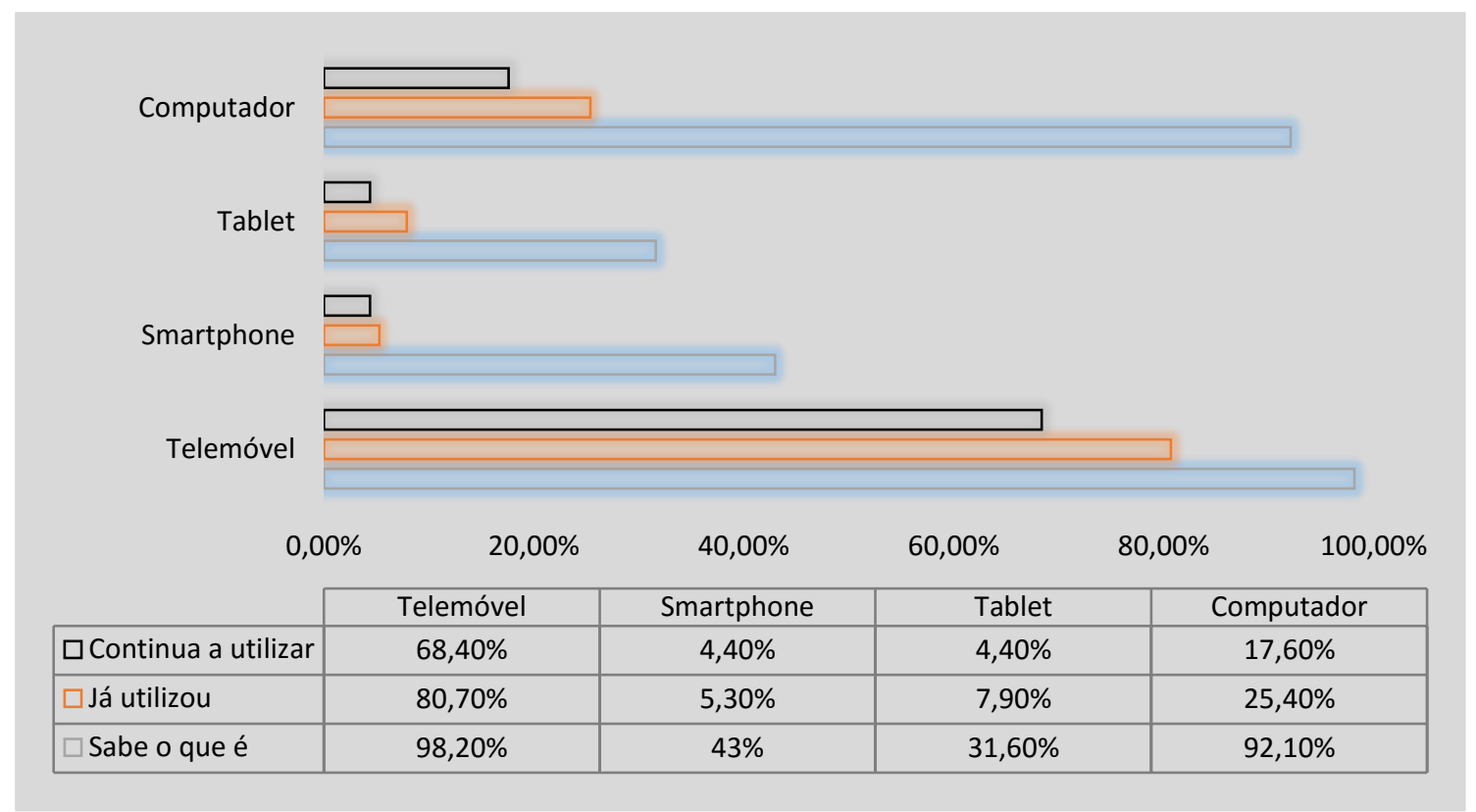

Figura 3 - Grau de utilização das TIC pelos idosos $(N=114)$

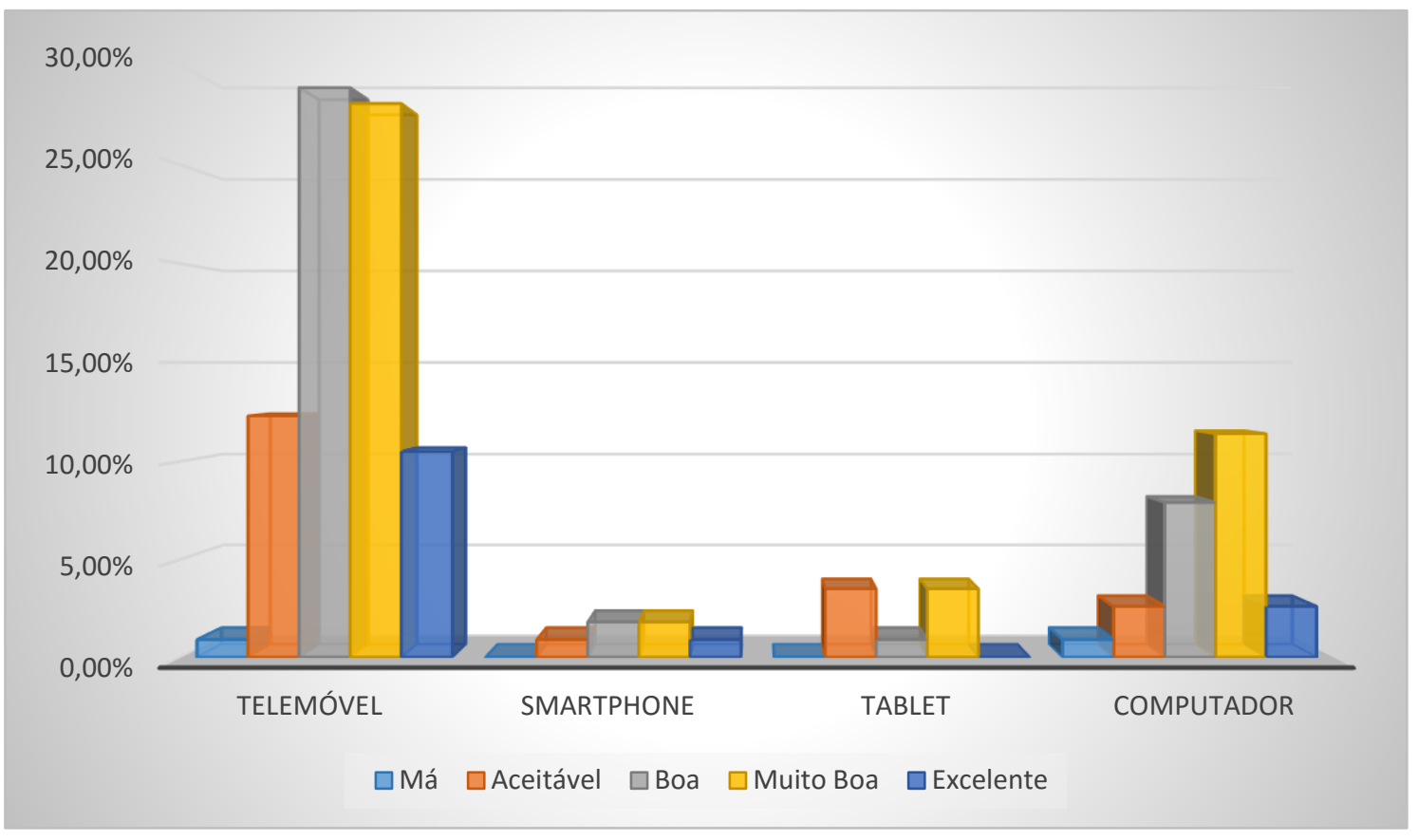

Figura 4 - Avaliação da utilização das TIC pelos idosos $(N=114)$ 


\subsection{Perceção do estado de saúde e grau de utilização das TIC}

Ao analisar a possivel relação entre a perceção do estado geral de saúde e o grau de utilização das TIC, os resultados parecem demonstrar uma associação estatisticamente significativa entre a avaliação do estado geral de saúde e o grau de utilização do telemóvel $\left(x^{2}=19.412 ; p=0.025\right)$, para um nível de significância de 5\%. Ao analisar a tabela de frequências, verifica-que a utilização do telemóvel é mais frequente entre aqueles que têm pior perceção do estado de saúde, efetivamente, dos 33 idosos que afirmaram usar o telemóvel "frequentemente", 19 consideram a sua saúde como "aceitável” (Tabela 3 ).

Tabela 3- Relação entre a perceção do estado de saúde e a utilização do telemóvel

\begin{tabular}{cccccccc}
\hline & Nunca & Raramente & Ocasionalmente & Frequentemente & Sempre & Total \\
\hline Má & 7 & 1 & 4 & 5 & 3 & 20 \\
\hline Aceitável & 4 & 3 & 9 & 19 & 6 & 41 \\
\hline Boa & 1 & 2 & 6 & 8 & 1 & 10 & 27 \\
\hline Muito Boa & 2 & 0 & 0 & 33 & 20 & 92 \\
\hline Total & 14 & 6 & 19 & & & 4 \\
\hline
\end{tabular}

Para além disso, não se verificou, com significância estatística, uma relação entre a perceção do estado geral de saúde e o grau de utilização do smartphone $\left(x^{2}=8.340 ; p=0.222\right)$, tablet $\left(x^{2}=5.725\right.$; $p=0.205)$ e computador $\left(x^{2}=3.134 ; p=0.582\right)$.

\subsection{Principais atividades/finalidades da utilização das TIC}

Quando questionados sobre as atividades e finalidades com que utilizam as TIC, destaca-se conversar com a família [49 idosos (43\%) fazem-no frequentemente, 17 (14.9\%) ocasionalmente e 12 (10.5\%) fazem-no sempre] e falar com os amigos [cerca de 37 idosos (32.5\%) fazem-no frequentemente]. Verifica-se, ainda, que o principal equipamento utilizado para estas finalidades é o telemóvel (67.5\% para conversar com a família e $51.8 \%$ para falar com amigos).

$\mathrm{Na}$ Tabela 4, encontram-se as respostas referidas pela amostra sobre as atividades desenvolvidas com as TIC, a frequência das mesmas, assim como, o equipamento mais utilizado para as realizar. 
Tabela 4 - Principais atividades realizadas pelos idosos com as TIC $(\mathrm{N}=114)$

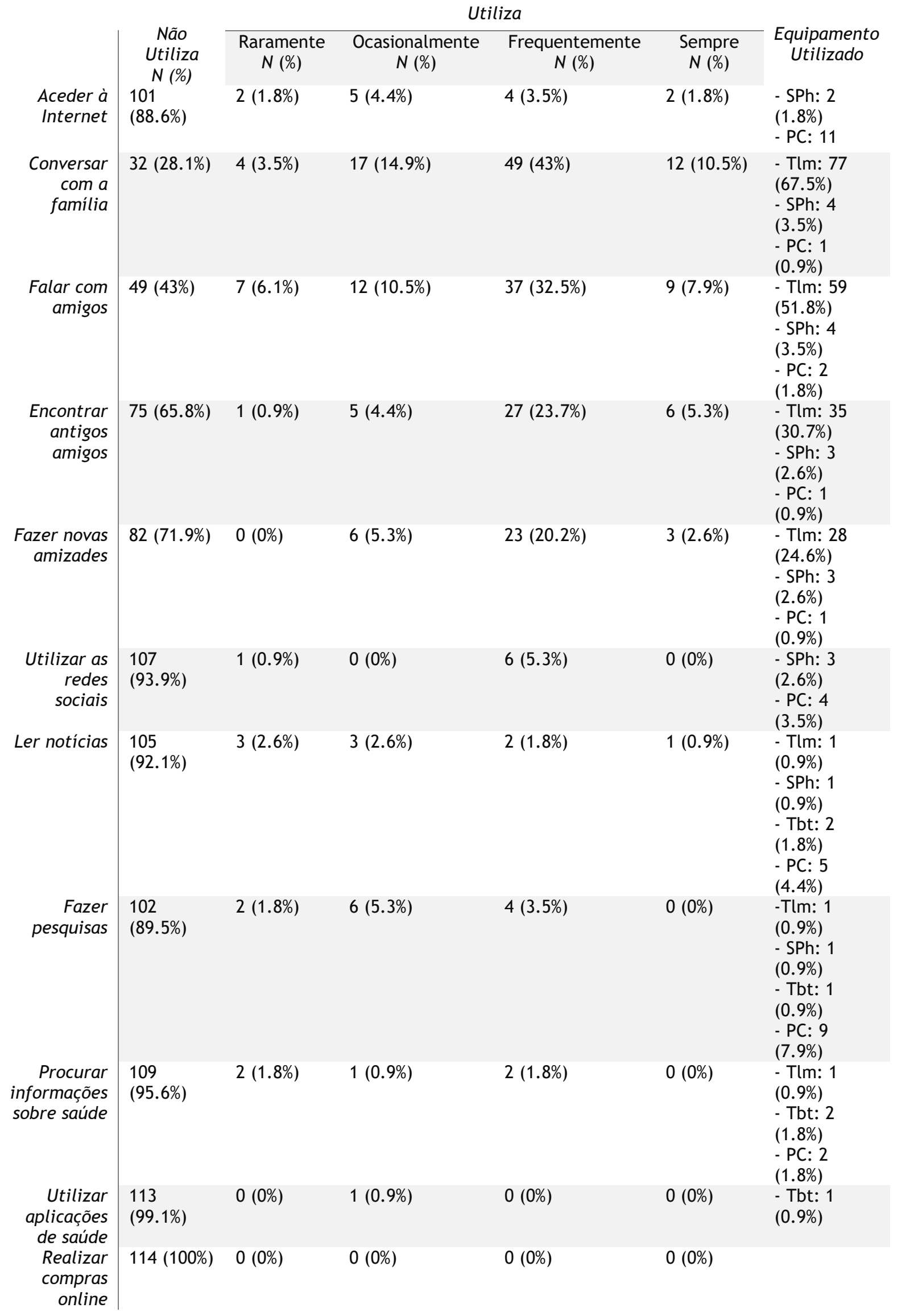



perceção do estado de saúde

\begin{tabular}{|c|c|c|c|c|c|c|}
\hline $\begin{array}{r}\text { Enviar e- } \\
\text { mails }\end{array}$ & $\begin{array}{l}107 \\
(93.9 \%)\end{array}$ & $2(1.8 \%)$ & $2(1.8 \%)$ & $3(2.6 \%)$ & $0(0 \%)$ & $\begin{array}{l}- \text { SPh: } 1 \\
(0.9 \%) \\
-P C: 6 \\
(5.3 \%)\end{array}$ \\
\hline $\begin{array}{l}\text { Ouvir } \\
\text { música }\end{array}$ & $\begin{array}{l}100 \\
(87.7 \%)\end{array}$ & 4 (3.5\%) & $3(2.6 \%)$ & $6(5.3 \%)$ & 1 (0.9\%) & $\begin{array}{l}\text { - Tlm: } 4 \\
\text { (3.5\%) } \\
\text { - SPh: } 2 \\
\text { (1.8\%) } \\
\text { - Tbt: } 3 \\
\text { (2.6\%) } \\
\text { - PC: } 5 \\
(4.4 \%)\end{array}$ \\
\hline $\begin{array}{r}\text { Escrever } \\
\text { textos }\end{array}$ & $\begin{array}{l}105 \\
(92.1 \%)\end{array}$ & $3(2.6 \%)$ & 4 (3.5\%) & $2(1.8 \%)$ & $0(0 \%)$ & $\begin{array}{l}\text {-Tlm: } 2 \\
(1.8 \%) \\
\text { - SPh: } 1 \\
(0.9 \%) \\
\text { - Tbt: } 2 \\
(1.8 \%) \\
\text { - PC: } 4 \\
(3.5 \%)\end{array}$ \\
\hline Ver vídeos & $\begin{array}{l}104 \\
(91.2 \%)\end{array}$ & $3(2.6 \%)$ & 4 (3.5\%) & $3(2.6 \%)$ & $0(0 \%)$ & $\begin{array}{l}\text { - Tlm: } 2 \\
(1.8 \%) \\
\text { - SPh: } 2 \\
(1.8 \%) \\
\text { - TBt: } 3 \\
(2.6 \%) \\
\text { - PC } 3(2.6 \%)\end{array}$ \\
\hline $\begin{array}{r}\text { Assistir a } \\
\text { filmes }\end{array}$ & $\begin{array}{l}111 \\
(97.4 \%)\end{array}$ & $1(0.9 \%)$ & $0(0 \%)$ & $2(1.8 \%)$ & $0(0 \%)$ & $\begin{array}{l}\text { - PC: } 3 \\
(2.6 \%)\end{array}$ \\
\hline
\end{tabular}

Os resultados mostram, para um nível de significância de 5\%, uma relação estatisticamente significativa entre a idade e o uso das TIC para conversar com a família $\left(x^{2}=36.181 ; p=0.015\right)$, pelo que, dos 49 idosos que dizem fazê-lo frequentemente, 39 têm mais de 80 anos.

\subsection{Primeira experiência com as TIC}

No que diz respeito ao primeiro contato com as TIC, 68 idosos $(59.6 \%)$ revelam que o fizeram por iniciativa própria e 26 (22.8\%) idosos referem ter sido incentivados por outras pessoas. Ainda sobre as primeiras interações, $46(40.4 \%)$ idosos afirmam que aprenderam a manusear os equipamentos sozinhos. Contudo, 40 (35.4\%) idosos confessam que, inicialmente, recorreram aos familiares para utilizar as TIC e $7(6.1 \%)$ recorreram a outros elementos, nomeadamente, amigos e vizinhos. 


\subsection{0 medo e as principais dificuldades na utilização das TIC}

Destaque-se que, cerca de 86 idosos revelam ter a quem recorrer se precisarem de ajuda no manuseamento das novas tecnologias. Os auxiliares da instituição são referidos por 76 idosos como os principais coadjuvantes, sendo os familiares e amigos também referidos por 9 idosos.

Quando questionados sobre possíveis medos na utilização das novas tecnologias, 82 idosos (71.9\%) negam apresentar algum tipo de receio e 70 idosos (61.4\%) referem sentir dificuldades na utilização destes novos "artefactos" tecnológicos. Na Figura 5, apresentam-se as principais dificuldades mencionadas e respetiva distribuição por frequência.

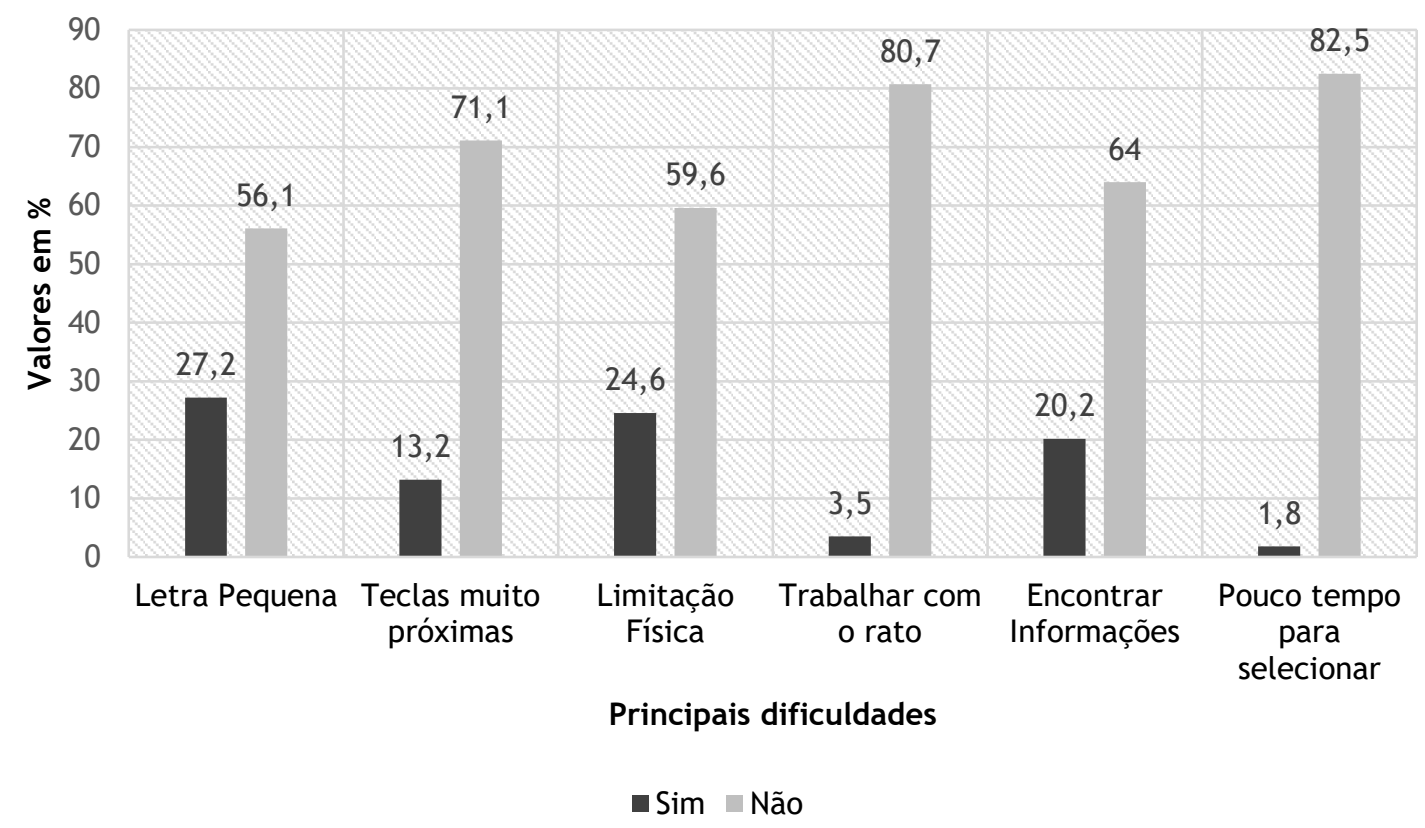

Figura 5 - Principais Dificuldades mencionadas na utilização das TIC N=114)

Os testes estatísticos realizados indicam, para um nível de significância de 5\%, a existência de uma associação estatisticamente significativa entre a idade e o medo de usar as novas tecnologias $\left(x^{2}=\right.$ 20.222; $p=0.027$ ), pelo que dos 28 idosos que respondem afirmativamente quando questionados sobre os receios no uso das TIC, 26 têm mais de 80 anos.

Destaca-se que, para o mesmo nível de significância, os resultados sugerem uma relação estatisticamente significativa entre a idade e a limitação física $\left(x^{2}=11.153 ; p=0.048\right)$, pelo que, dos 28 idosos que admitem apresentar uma limitação física que complica o uso das TIC, 20 têm mais de 80 anos, o que pode correlacionar-se com a maior morbilidade física que estes apresentam. 


\subsection{Interesse e envolvimento desejável em relação às TIC}

No que diz respeito à importância que atribuem às TIC, 103 idosos $(90.4 \%)$ consideram-nas importantes no quotidiano. Não obstante, quando questionados sobre o interesse que apresentam na sua utilização, 52 (45.6\%) negam qualquer interesse, opondo-se aos 62 idosos que admitem ter interesse no uso das TIC (54.4\%) (Figura 6).

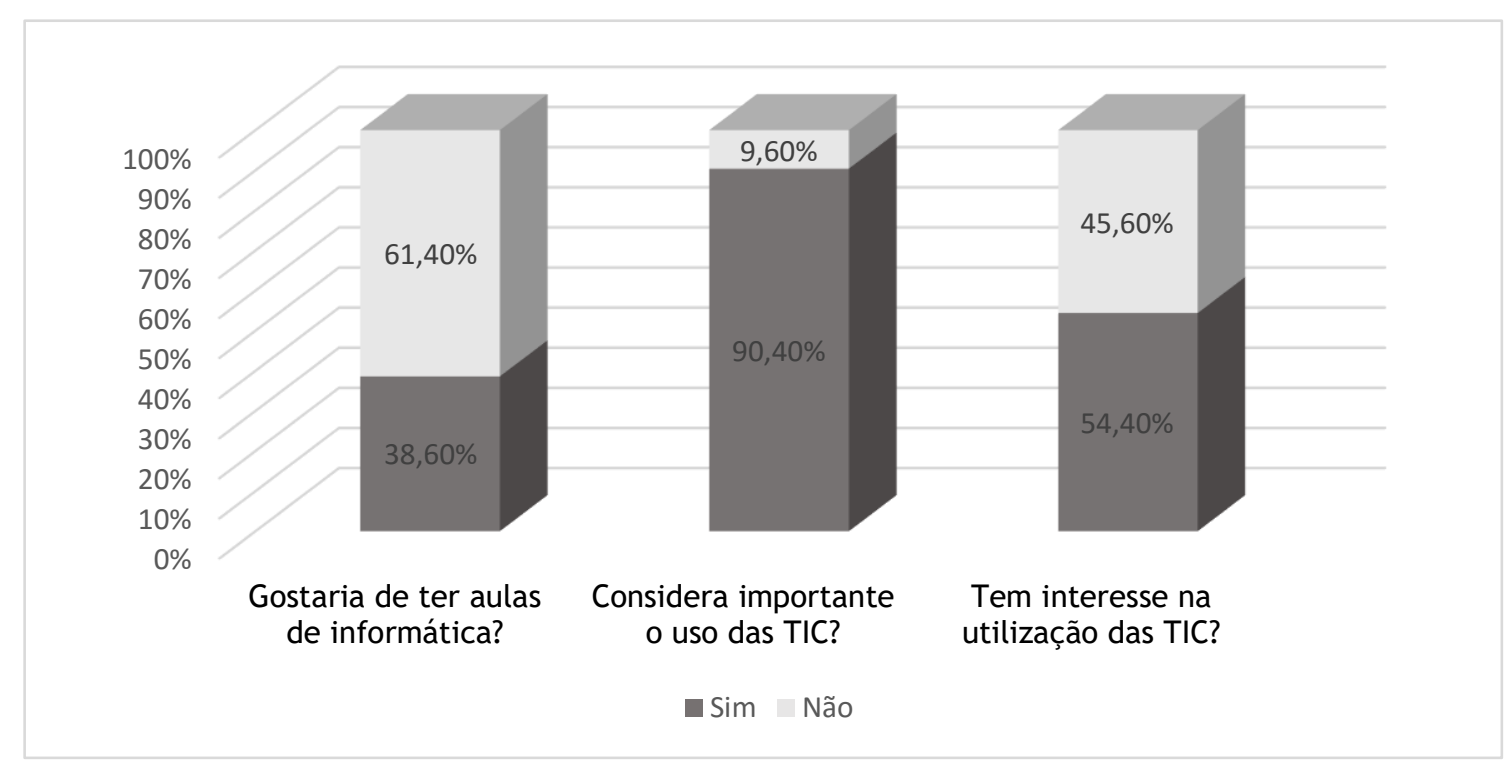

Figura 6 - Interesse dos idosos na utilização das TIC $(N=114)$

Para um nível de significância de $5 \%$, os resultados sugerem uma relação estatisticamente significativa entre o interesse em participar em aulas de informática e algumas variáveis sociodemográficas, como a idade $\left(x^{2}=19.636 ; p=0.001\right)$, dos 70 idosos que negam qualquer interesse, 55 têm mais de 80 anos, o género $\left(x^{2}=19.636 ; p=0.001\right)$, dos 44 idosos que afirmam querer participar em aulas de informática, 33 são do género feminino, e o meio $\left(x^{2}=19.636\right.$; $p=0.001$ ), do total de 70 idosos que não quer ter aulas, 46 são do meio rural. 


\subsection{Caraterísticas de um equipamento "ideal”}

Quando questionados sobre quais as caraterísticas que facilitariam a utilização das novas tecnologias, as respostas foram as representadas na Figura 7.

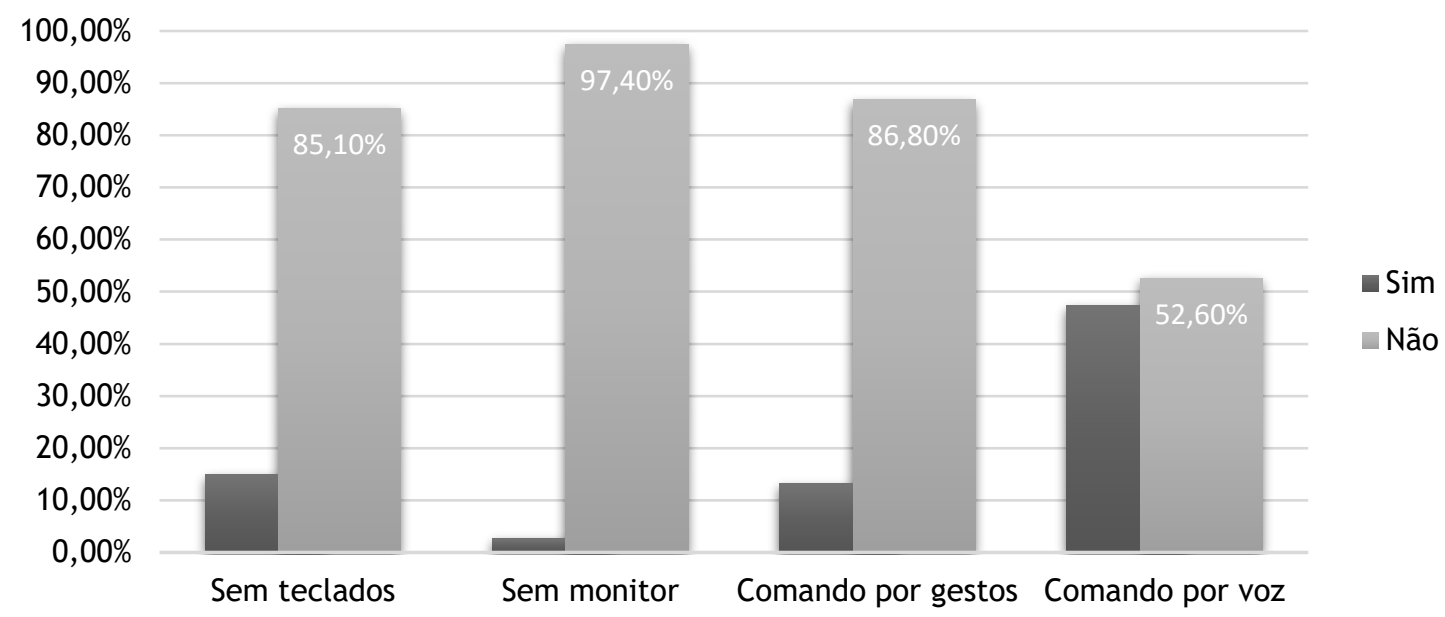

Figura 7 - Caraterísticas de um equipamento "ideal" ( $N=114)$

\subsection{Medo da Internet}

A maioria dos idosos (67.5\%) nega ter medo ou receio da Internet e sua utilização, todavia aqueles que respondem afirmativamente a esta questão, admitem que o seu receio decorre, maioritariamente, do desconhecimento face às TIC.

Para um nível de significância de $5 \%$, os resultados sugerem uma relação estatisticamente significativa entre o medo de navegar na Internet e o género $\left(x^{2}=12.378 ; p=0.002\right)$, pelo que, dos 35 idosos que admitem ter algum receio, 31 são do género feminino. 


\section{Discussão}

Tendo em conta que os dados obtidos são provenientes de uma amostra de conveniência, existem importantes limitações na discussão e análise dos resultados. Não obstante, surgem questões importantes que poderão levar ao desenvolvimento de investigações futuras com amostras mais representativas.

No que diz respeito às caraterísticas sociodemográficas da amostra, verifica-se que 79 idosos são do género feminino (69.3\%), o que está de acordo com as estimativas sobre a distribuição etária por género, do Instituto Nacional de Estatística (INE), recenseamento de 2011 (20). Ainda, sobre a literacia da amostra, verifica-se que a resposta mais frequentemente mencionada é a " 4 a classe", o que se assemelha aos dados encontrados na PORDATA - Base de dados de Portugal Contemporâneo(21).

Relativamente ao estado de saúde dos participantes deste estudo, 99 idosos (86.8\%) apresentam patologia cardiovascular e 63 (55.3\%) têm patologia do foro neurológico. Salientar que estes resultados se encontram em conformidade com os dados apresentados no Plano Regional de Saúde de 2016, onde se identificam como principais morbilidades as alterações no metabolismo dos lípidos, a hipertensão, as perturbações depressivas e a diabetes(22). Destaque-se ainda que as classes de fármacos mais utilizadas estão em consonância com a prevalência destas patologias e com estudos nacionais realizados no âmbito do consumo de medicamentos e polimedicação em Portugal, que indicam que os anti-hipertensores são das classes de fármacos mais utilizadas(23).

Em relação à perceção do estado de saúde, constata-se que 44 idosos (38.6\%) a avaliam como “aceitável" e 38 idosos (33.3\%) como "boa". Segundo a literatura, esta é reconhecida como um importante indicador do estado de saúde, cada vez mais valorizado no planeamento e adoção de comportamentos saudáveis $(24,25)$. Estes resultados corroboram as indicações prévias de um estudo, realizado em Portugal em dezembro de 2011 sobre perceção do estado de saúde da pessoa idosa institucionalizada, na qual a maioria dos idosos também avaliou a sua saúde como "aceitável" e "boa"(26). Se, por um lado, estes resultados parecem indicar que a institucionalização dos idosos não implica que estes percecionem a sua saúde de forma negativa, por outro lado, permitem depreender que há uma panóplia de intervenções que devem ser executadas de forma a melhorar a perceção dos idosos sobre o seu estado de saúde(26).

No que concerne ao grau de utilização das TIC, verifica-se que dos 114 participantes da amostra, 20 não utilizam qualquer equipamento tecnológico, enquanto 94 idosos utilizam pelo menos um dos equipamentos de TIC avaliados. Os relatórios estatísticos da Organização para a Cooperação e Desenvolvimento Económico (OCDE) evidenciam que os idosos são o segmento da população que mais cresce entre os utilizadores das novas tecnologias, sendo que vivem de forma mais 
ativa o seu envelhecimento, os que mais procuram ferramentas e alternativas que thes asseguram maior autonomia $(27,28)$. Neste sentido, os resultados deste estudo apontam para um elevado número de idosos institucionalizados utilizadores de TIC, ainda que seja maioritariamente o telemóvel, o que pode corroborar a crescente utilização das TIC por este grupo etário. A par disso, acresce a consciencialização dos benefícios da utilização das TIC, nomeadamente, na promoção da inclusão social na Terceira Idade, no processo de socialização e na conservação do bem-estar dos indivíduos(27). A redução da rede social e as barreiras físicas que limitam a capacidade das pessoas idosas institucionalizadas se encontrarem fisicamente com pessoas significativas podem ser atenuadas pela utilização das TIC para estabelecimento e manutenção de relações interpessoais. 0 facto dos resultados deste estudo apontarem para um número significativo de utilizadores de TIC, ainda que seja uma utilização rudimentar, reforça as potencialidades que a implementação, otimização, treino e divulgação das TIC apresentam como equipamento e estratégia de relacionamento interpessoal, com possível impacto no bem-estar e saúde(27).

O telemóvel é o equipamento de TIC mais utilizado pelos idosos, sendo que 92 referem já o ter utilizado e 78 continuam a utilizá-lo, ou seja, $68.40 \%$ da amostra, valor um pouco mais elevado do que o obtido num estudo realizado em Castelo Branco, em 2014, na qual 53.6\% da amostra utilizava esta tecnologia(29). Este resultado está em consonância com os dados referidos anteriormente na qual se constata uma utilização crescente das TIC pelos idosos(7). 0 estudo evidencia, com significância estatística, que aqueles que utilizam mais frequentemente 0 telemóvel estão em faixas etárias mais elevadas, opondo-se aos resultados obtidos no estudo referido anteriormente, na qual a utilização do telemóvel era maior em idades menores(29). Por um lado, estes dados podem correlacionar-se com o facto do intervalo de idades mais representativo da amostra, deste estudo, ser entre os 85-89 anos, o que difere do estudo referido, na qual o intervalo de idades mais representativo era entre os 65 e os 80 anos(29). Por outro lado, pode haver maior necessidade de recorrer às TIC ao longo do tempo, de forma a colmatar as limitações impostas pelas comorbilidades que se vão instalando, sendo a idade interpretada como uma motivação acrescida no desenvolvimento de estratégias que assegurem maior bem-estar ao idoso e não motivo de exclusão do mundo digital(7). Observa-se, também, que aqueles que classificam a utilização do telemóvel como "muito boa" e "excelente" são sobretudo idosos com mais de 80 anos, o que se pode relacionar com a maior utilização do telemóvel acima desta faixa etária.

A segunda TIC mais usada pelos participantes deste estudo é o computador, pelo que 29 idosos já o utilizaram alguma vez e 20 (17.10\%) continuam a utilizá-lo no quotidiano, valor superior ao obtido no estudo supracitado(29). Os resultados sugerem que aqueles que utilizam mais frequentemente o computador cresceram no meio urbano e apresentam maiores habilitações literárias. Este resultado está em conformidade com alguns resultados da literatura, na qual se constata que indivíduos com mais literacia e de zonas de cariz urbano apresentam maior 
contacto com o computador, nomeadamente, no mercado de trabalho, promovendo a aquisição de competências digitais e rotinas que promovem a sua maior utilização no quotidiano(29).

Quanto ao smartphone, 64 idosos referem desconhecer esta tecnologia e, entre aqueles que conhecem, 5 é o número de idosos que o utilizam, ou seja, 4.4\% da amostra, opondo-se a outras investigações na qual o número de idosos a utilizar um smartphone é superior(30). Acerca do tablet, 9 participantes já o utilizaram e 5 continuam a fazê-lo, no entanto, cerca de $68.4 \%$ dos idosos não sabe o que é, valor muito semelhante ao encontrado num estudo realizado nos Estados Unidos, em 2014(31).

Relativamente à relação entre a perceção do estado de saúde e o grau de utilização das TIC, os resultados sugerem, com significância estatística, que a utilização do telemóvel é mais frequente entre aqueles que têm pior perceção do estado de saúde. De acordo com a literatura, existem vários fatores que influenciam a perceção do estado de saúde, nomeadamente, depreende-se que aqueles que têm uma visão mais positiva do envelhecimento, apresentam melhor auto-perceção de saúde e são mais independentes(18). Por outro lado, aqueles que relatam pior perceção do estado de saúde, devido ao maior isolamento social, maior deteorização da sua saúde e menor participação na comunidade, podem considerar o telemóvel como uma ferramenta indispensável para as relações sociais e um aliado em situações de emergência, permitindo estabelecer contacto em qualquer momento e lugar, o que favorece a sua utilização no quotidiano e pode justificar os resultados obtidos(17).

Acerca da utilização das TIC, enumeram-se vários benefícios para a população idosa, nomeadamente, redução do isolamento social, maior envolvimento na comunidade $e$ intergeracional, redução do declínio cognitivo e maior capacidade mental e emocional(32). Tal parece estar em conformidade com os resultados deste estudo, no qual se verifica que, frequentemente, 49 idosos (43\%) recorrem às TIC para conversar com familiares e 37 (32.5\%) fazem-no para falar com amigos. 0 facto de a institucionalização aumentar em indivíduos com mais de 75 anos, aumentando a necessidade de recorrer às TIC para diminuir a distância e manter o laço familiar, pode correlacionar-se com os resultados, que sugerem que aqueles que mais frequentemente utilizam as TIC para conversar com a família têm mais de 80 anos(4).

No entanto, há alguns resultados que se destacam, como o acesso à Internet, na qual, 101 idosos (82.6\%) referem nunca o ter feito, um valor muito superior, por exemplo, a um estudo realizado na Espanha em 2011, na qual a percentagem de idosos que não utilizavam a Internet era de 54.8\%(33). Não obstante, num estudo realizado por Lelkes, em 2013, várias razões são apontadas para a baixa utilização da Internet, que podem, em parte, justificar os resultados encontrados, nomeadamente, baixa literacia, dificuldades de aprendizagem e dificuldades económicas(34). Os resultados indicam, ainda, que, dos 114 participantes da amostra, nenhum realiza compras online, 113 nunca utilizaram aplicações de saúde e 107 nunca utilizaram as redes sociais ou enviaram e-mails, valores muito discrepantes dos encontrados em diferentes 
estudos, nomeadamente no estudo já mencionado, realizado em Castelo Branco, na qual 36.6\% da amostra utilizava o computador para jogar e enviar correio eletrónico(29).

Em relação à aquisição das novas tecnologias, 68 idosos (59.6\%) revelam que o fizeram por iniciativa própria, enquanto 26 idosos $(22.8 \%)$ referem ter sido incentivados por outras pessoas. Estes dados são discordantes dos resultados encontrados no estudo realizado em 2011 com idosos em Castelo Branco, na qual a maioria (54.2\%) refere ter adquirido um telemóvel a pedido de familiares(29). Coloca-se a hipótese desta discrepância estar correlacionada com o desfasamento temporal entre os dois estudos e com o maior interesse dos idosos em aprender, mantendo-se atualizados sobre o contexto que os rodeia(10).

Ressaltar que, 82 idosos negam ter medo de utilizar as TIC e os resultados sugerem, com significância estatística, uma relação entre a idade e o medo de usar as novas tecnologias, sendo que, dos 28 idosos que afirmam ter receios no uso das TIC, 26 têm mais de 80 anos. Estes dados estão em conformidade com o estudo realizado com idosos, em Castelo Branco, na qual o número de idosos que admitem ter medo em usar as TIC era bastante residual(29). Segundo a literatura, o desconhecimento e inexperiência dos idosos na utilização das TIC justifica alguma insegurança e medo de danificar os equipamentos ou alterar a sua configuração, que alguns idosos referem(27).

No que se refere ao manuseamento das novas tecnologias, 70 idosos admitem ter algumas dificuldades. De facto, 31 idosos referem que a letra pequena de alguns aparelhos dificulta o seu uso, 28 idosos referem apresentar limitações físicas (como dificuldades de visão, audição e memorização) que complicam a utilização das TIC e 23 admitem ter dificuldades em encontrar a informação que necessitam. Estes resultados são similares aos mencionados noutros estudos que apontam a memorização de comandos, problemas com o rato e teclado, tamanho da letra, menor agilidade física e mental, iliteracia e medo como as principais dificuldades na utilização das TIC pelos idosos $(27,28,33)$. Neste sentido, estes resultados sugerem aspetos das TIC que podem ser adaptados às dificuldades de alguns perfis de pessoas idosas para que seja possível utilizarem as TIC.

Quanto à participação em aulas de informática, 44 idosos (38.6\%) confessam que gostavam de ter essas aulas, um valor ligeiramente superior ao encontrado noutros estudos(29). Segundo a literatura, alguns idosos têm a ideia preconcebida de que as novas tecnologias são para os mais jovens, admitindo que já "não tem idade" para aprender(29). Tal pode justificar os resultados deste estudo, na qual se verificou um menor interesse em participar em aulas de informática em idades mais avançadas. Em relação ao género e ao meio, estes resultados estão em conformidade com os dados obtidos no estudo de 2011 anteriormente mencionado, na qual se evidencia que as senhoras tem maior interesse em ter aulas de informática e indivíduos que crescem num meio rural, talvez por terem menor acesso e menor grau de utilização do computador, manifestam menor vontade em ter essas aulas (29). Realçar que, o ensino aos 
idosos requer métodos de aprendizagem específicos, devido ao ritmo de aprendizagem mais lento, diferentes graus de motivação e maior morbilidade física e mental(7).

Ainda assim, 62 idosos manifestam interesse na utilização das TIC, em parte pelas várias vantagens que tal acarreta e 103 idosos (90.4\%) referem que as novas tecnologias são importantes, um valor muito superior ao mencionado no estudo referido $(29,32)$. Segundo a literatura, mesmo as pessoas mais velhas com limitada utilização das TIC apresentam atitudes positivas face às novas tecnologias, reconhecendo-as como ferramentas de aprendizagem e entretenimento, úteis na integração e comunicação social(33).

Quando questionados sobre as caraterísticas que definem o seu "equipamento ideal", 54 idosos referem que preferiam um equipamento que pudesse ser "comandado por voz". De facto, cabe aos responsáveis pela criação das novas tecnologias, desenhar e introduzir no mercado equipamentos que facilitem a interação com os seus utilizadores e que sejam facilmente percetíveis por todos os indivíduos, independentemente, da faixa etária(35).

Sobre a Internet, 77 idosos revelam não ter medo de navegar na Internet e dos 35 idosos que admitem ter algum receio, 31 são do género feminino. Estes dados opõe-se aos resultados do estudo de 2011 já referido, no qual se identificava que os homens apresentavam mais receios, em parte, devido ao facto de serem eles os maiores utilizadores da Internet e, talvez, por isso, mais experientes e conscientes dos perigos(29). Segundo a bibliografia, a Internet fomenta o estabelecimento de novos vínculos, favorecendo o desenvolvimento psicossocial do idoso, sendo que, aqueles que utilizam a Internet referem mudanças significativas, como a valorização pessoal, comunicação, informação e lazer(15). Porém, no início, os idosos manifestam algum medo e resistência em aceder e utilizar a Internet, em parte justificada pela inabilidade com as TIC, baixa autoestima e medo do desconhecido (15). Ainda assim, apesar do receio, verificase um reconhecimento das vantagens e importância das TIC e da Internet(15). 
Experiências de pessoas idosas institucionalizadas sobre as Tecnologias de Informação e Comunicação (TIC) e sua perceção do estado de saúde 


\section{Potencialidades e Limitações}

Este trabalho tem um caráter inovador, na medida em que avalia o conhecimento e o grau de utilização das novas tecnologias, numa população de uma faixa etária que nasceu previamente à era digital e, por isso, menos familiarizada com ela. Tendo a revisão da literatura efetuada no âmbito desta dissertação, indicado escassez de estudo sobre esta temática que, de forma mais direta ou indireta, pode ter um impacto significativo na saúde e qualidade de vida com que se envelhece em contexto institucional, o seu debate e investigação é crucial.

Tendo em conta que as TIC albergam várias funcionalidades, é interessante perceber qual o impacto que elas apresentam no dia-a-dia dos idosos institucionalizados e de que forma é que podem contribuir para melhorar a sua qualidade de vida, promovendo o envelhecimento ativo.

Ainda, ao abordar as principais dificuldades no manuseamento das TIC e quais as caraterísticas consideradas importantes num "equipamento ideal”, este estudo abre caminho para a criação de novos equipamentos que possam facilitar a interação entre os idosos e as TIC, apontando para a voz como meio fundamental da comunicação mas também da interface com os equipamentos.

Para além disso, o presente estudo, no qual só participaram indivíduos institucionalizados, com idade igual ou superior a 65 anos, foi baseado na sua perceção do estado de saúde, revelando um grupo de idosos que, maioritariamente, considera a sua saúde como "aceitável". Tal pode sugerir maior necessidade de criar estratégias e promover intervenções que melhorem a forma como o idoso perceciona a sua saúde.

Relativamente às limitações, devido ao baixo custo e maior facilidade operacional, este estudo foi conduzido junto de uma amostra por conveniência, ou seja, os participantes encontravamse prontamente disponíveis, não tendo sido utilizado um critério estatístico para a sua seleção. Desta forma, a representatividade da amostra fica comprometida, não sendo possível estabelecer afirmações gerais com rigor estatístico sobre a população. Para além disso, não é possível utilizar ferramentas estatísticas, como a margem de erro e o nível de confiança, para medir a precisão dos resultados.

Outra limitação deste estudo é a reduzida dimensão da amostra ( $N=114)$, comparativamente ao número total de idosos portugueses institucionalizados, comprometendo, mais uma vez, a representatividade da amostra. Portanto, deve-se aumentar o número de participantes em próximas investigações.

Ainda, como limitação deste estudo, verifica-se que nalguns casos os dados recolhidos relativamente à informação clínica (patologias e medicação) foram baseados unicamente no autorrelato dos participantes e não nos processos clínicos. 
Experiências de pessoas idosas institucionalizadas sobre as Tecnologias de Informação e Comunicação (TIC) e sua perceção do estado de saúde 


\section{Conclusão}

O envelhecimento é inevitável, por isso, é imperativo assegurar as melhores condições de saúde e fomentar estratégias que promovem a qualidade de vida, integração e inclusão social naquela que se está a tornar a faixa etária predominante da nossa sociedade.

Face aos dados recolhidos, no âmbito desta investigação, no distrito de Castelo Branco e Viseu, pode afirmar-se que a maioria dos idosos envolvidos perceciona o seu estado geral de saúde como "aceitável”, não sendo esta variável influenciada, com significância estatística, pelas variáveis sociodemográficas. Desta forma, seria importante investigar, futuramente, quais os determinantes que influenciam esta avaliação, qual o impacto que a mesma apresenta no quotidiano dos idosos e de que forma pode ser melhorada.

Também, pode concluir-se que o manuseamento das TIC não é uma prática frequente dos cidadãos mais idosos (65 ou mais anos) institucionalizados, exceto o telemóvel, que é utilizado por cerca de $68 \%$ da amostra. As restantes tecnologias, ou seja, o smartphone, o tablet e o computador apresentam um grau de utilização muito inferior, sendo maioritariamente ignoradas, o que pode correlacionar-se com a iliteracia digital dos idosos. Não obstante, os participantes admitem ter interesse na utilização das TIC, reconhecendo a sua importância e aplicabilidade, nomeadamente no que diz respeito à comunicação com familiares e amigos.

É importante realçar que aqueles que utilizam mais frequentemente o telemóvel apresentam pior perceção do estado de saúde, o que pode correlacionar-se com a maior necessidade de utilizar as novas tecnologias há medida que as comorbilidades se vão instalando. De facto, as TIC podem colmatar as limitações que vão sendo impostas pela idade, promovendo maior autonomia e bem-estar ao idoso.

As inúmeras vantagens da utilização das TIC no quotidiano, nomeadamente, maior comunicação e integração social, maior proximidade e facilidade no acesso aos cuidados de saúde, maior capacitação pessoal e bem-estar, são premissas que devem fomentar a utilização das TIC pelos idosos e a implementação de estratégias que facilitem o seu acesso e aprendizagem. Seria interessante construir mecanismos que pudessem incrementar esta interação, explorando os seus benefícios para esta faixa etária, sem ignorar as idiossincrasias típicas dos mais velhos. De facto, só assim fica asseverada a verdadeira inclusão digital e, por conseguinte, a verdadeira inclusão social. 
Experiências de pessoas idosas institucionalizadas sobre as Tecnologias de Informação e Comunicação (TIC) e sua perceção do estado de saúde 


\section{Referências Bibliográficas}

1. Esgueira PIB. Envelhecimento Ativo : um estudo sobre os hábitos de vida dos idosos residentes em meio rural [Dissertação de mestrado não publicada]. Bragança: Instituto Politécnico de Bragança - Escola Superior de Educação; 2013; [cited 2018 Dec 22]. Available from: https://bibliotecadigital.ipb.pt/bitstream/10198/9230/1/Patr\%C3\%ADcia\%20Esgueira.pdf

2. Blažun H, Vošner J, Kokol P, Saranto K, Rissanen S. Elderly people's interaction with advanced technology. Studies in Health Technology and Informatics. 2014;201:1-10.

3. ANTUNES, M. C.; ABREU, V. As novas tecnologias na promoção do envelhecimento bemsucedido. Ens. Tecnol. R., Londrina, v. 1, n. 1, p. 3-15, jan./jun. 2017. Disponível em: <https://periodicos.utfpr.edu.br/rbqv/article/view/5885>. Acesso em: 2017.

4. Neves, H. M. F. " Causas e Consequências da Institucionalização de Idosos, Estudo tipo série de casos" [Dissertação de mestrado]. Covilhã: Universidade da Beira Interior; 2012; [cited 2019 Jan 8]. Available from: https://ubithesis.ubi.pt/bitstream/10400.6/1209/1/CAUSAS_CONSEQUENCIAS_INSTITUCIONAL IZAÇAO_IDOSOS.pdf

5. Lourenço, M. P. R. "INSTITUCIONALIZAÇÃO DO IDOSO E IDENTIDADE" [Dissertação de mestrado não publicada]. Portalegre: Instituto Politécnico de Portalegre - Escola Superior de Educação de Portalegre e Escola Superior de Saúde de Portalegre; 2014; [cited 2019 Jan 8]. Available from: http://hdl.handle.net/10400.26/9205

6. Direcção-Geral da Saúde. Programa nacional para a saúde das pessoas idosas. Direcção-Geral da Saúde [Internet]. 2004;1-24. Available from: http://www.fafit.com.br/revista/index.php/fafit/article/viewFile/16/12

7. Pereira C, Neves R. Os idosos na aquisição de competências TIC. Educ Formação Tecnol ISSN 1646-933X [Internet]. 2011;4(2):15-24. Available from: http://www.eft.educom.pt/index.php/eft/article/view/251\%5Cnhttp://www.eft.educom.pt /index.php/eft/article/download/251/142

8. Kachar V. Envelhecimento e perspectivas de inclusão digital. Rev Kairós Gerontol [Internet]. 2010;13(2):131-47. Available from: http://revistas.pucsp.br/index.php/kairos/article/view/5371

9. Marc Prensky P. Nativos Digitais, Imigrantes Digitais. Horiz [Internet]. 2001;9(5). Available from: www.hungry.com 
10. SILVA, M. G.; BATISTA SCF. Novas Tecnologias na Educação. Rev Novas Tecnol na Educ. 2015;13(1):1-10.

11. Sales MB de, Amaral MA, Junior IGS, Sales AB de. Tecnologias de Informação e Comunicação via Web: Preferências de uso de um grupo de usuários idosos. Rev Kairós Gerontol. 2014;17(3):59-77.

12. Portal, R. Portugal implementa tecnologias para idosos [Internet]. 2015 [cited 2019 Fev 11]; Available from: http://www.portaldoenvelhecimento.com/tecnologias/item/3551-portugalimplementa-tecnologias-para-idosos?tmpl=component\&print=1 1/3

13. Blažun H, Saranto K, Kokol P, Vošner J. Information and communication technology as a tool for improving physical and social activity of the elderly. NI 2012 11th Int Congr Nurs Informatics, June 23-27, 2012, Montreal Canada Int Congr Nurs Informatics (11th 2012 Montréal, Québec) author [Internet]. 2012;2012:26. Available from: www.pubmedcentral.nih.gov/articlerender.fcgi?artid=PMC3799169

14. Jantsch A, Machado LR, Behar PA, Lima JV de. As Redes Sociais e a Qualidade de Vida: os Idosos na Era Digital. Rita [Internet]. 2012;7(4):173-9. Available from: http://rita.det.uvigo.es/201211/uploads/IEEE-RITA.2012.V7.N4.A2.pdf

15. Verona Silvana Marinaro, Cunha Cristiane da, Pimenta Gustavo Camps, Buriti Marcelo de Almeida. Percepção do idoso em relação à Internet. Temas psicol. [Internet]. 2006 Dez [citado 2019 Abr 01]; 14(2): 189-197. Disponível em: http://pepsic.bvsalud.org/scielo.php?script=sci_arttext\&pid=S1413389X2006000200007\&lng=pt.

16. ORDONEZ, Tiago Nascimento et al. Idosos on-line: exemplo de metodologia de inclusão digital. Revista Kairós: Gerontologia, [S.I.], v. 15, p. 215-234, maio 2013. ISSN 2176-901X. Disponível em: <https://revistas.pucsp.br/kairos/article/view/15250>. Acesso em: 02 abr. 2019.

17. Zikic L, Jankelic S, Milosevic DP, Despotovic N, Erceg P, Davidovic M.Self-perception of heatlth in the oldest subjects. Archives of Gerontology and Geriatrics [Internet]. 2009;1:245-9. doi: 10.1016/j.archger.2009.09.036

18. Henchoz K, Cavalli S, Girardin M. Health perception and health status in advanced old age: A paradox of association. J Aging Stud. 2008;22(3):282-90.

19. Maroco J. Análise Estatística com o SPSS statistics. 5a Edição. Edições ReportNumber; 2011. 
20. Instituto Nacional de Estatística. População residente (censo 2011), por sexo e por grupo etário. [Internet] [cited 2019 janeiro 30]. Available from: https: / / ine.pt/xportal/xmain?xpid=INE\&xpgid=ine_p_etarias\&menuBOUI=13707095\&contexto $=$ pe\&selTab=tab4

21. PORDATA. População residente com 15 a 64 anos e 65 e mais anos: por nível de escolaridade completo mais elevado. [Internet] 2003;1-2 [cited 2019 mar 16]. Available from: https://www.pordata.pt/Portugal/Popula\%C3\%A7\%C3\%A30+residente+com $+15+a+64+a n o s+e+6$ 5+e+mais+anos+por+n\%C3\%ADvel+de+escolaridade+completo+mais+elevado-332

22. Neto M, Pimentel JP, Tavares A, Araújo FO, Guerreiro AC. Perfil Regional de Saúde da Região Centro. [Internet] 2016; [cited 2019 mar 16]. Available from: http://www.arscentro.minsaude.pt/Documents/informa\%C3\%A7\%C3\%B5es/2017/PeRS_Centro_2016.pdf

23. Pinto A, Lobo V, Bação F, Bacelar-Nicolau H. O consumo de medicamentos e a polimedicação em Portugal. 2 Vol - A Via Desenvolv para Vencer a Cris [Internet]. 2010;(2009):177/180. Available from: http://www.springerlink.com/index/10.1208/s12248-009-9106-3

24. Anes E, Fernandes A, Antão C, Magalhães C, Geraldes M. Comparação da qualidade de Vida de idosos residentes em meio rural e urbano. Dilemas atuais e desafios Futuros | I Congresso de Cuidados Continuados da Unidade Longa Duração e Manutenção St Maria Maior [Internet]. 2012;11. Available from: http://hdl.handle.net/10198/8344

25. Appels A, Bosma H, Grabauskas V, Gostautas A, Sturmans F. Self-rated health and mortality in a Lithuanian and a Dutch population. Soc Sci Med [Internet]. 1996;42(5):681-9. doi:10.1016/0277-9536(95)00195-6

26. Ferreira, Z. (2011) Perceived Health Status of Institutionalized Elderly. Journal of Aging \& Inovation, 1 (1): 23-29

27. Azevedo C. TIC e sociedades cada vez mais envelhecidas: uma contextualização de estudos no Brasil, em Portugal e em outros países. Verso e Reverso [Internet]. 2017;31(76). doi: 10.4013/ver.2016.31.76.02.

28. Fernandes F, Ferreira B. Inclusão Digital de Idosos: Um estudo sobre a Realidade do Município de Belém (Pa). RENOTE - Revista Novas Tecnologias na Educação [Internet].2011;4:1-10. doi.org/10.22456/1679-1916.30912

29. Gil H. Os cidadãos mais idosos (65+ anos) do concelho de Castelo Branco na utilização das TIC, e-Saúde e e-Governo Local [Relatório de Investigação de Pós-Doutoramento]. Lisboa: Instituto Superior de Ciências Sociais e Políticas; 2014; [cited 2019 fev 12]. Available from: https://repositorio.ipcb.pt/bitstream/10400.11/2463/1/Texto completo ccapa.pdf 
Experiências de pessoas idosas institucionalizadas sobre as Tecnologias de Informação e Comunicação (TIC) e sua perceção do estado de saúde

30. Moller F. Uso do smartphone por pessoas da terceira idade: a utilização de apps para operações bancárias [Internet]. 2017. p. 26. Available from: https://riuni.unisul.br/handle/12345/2079

31. Delello JA, McWhorter RR. Reducing the Digital Divide: Connecting Older Adults to iPad Technology. J Appl Gerontol. 2017;36(1):3-28. doi 10.1177/0733464815589985

32. Bechmann A, Lomborg S. Social support and "playing around": An examination of how older adults acquire digital literacy with tablet computers. New Media Soc [Internet]. 2013;15(5):76581. doi: $10.1177 / 0733464815609440$

33. Antonio González, María Paz Ramírez, and Vicente Viadel, "ICT Learning by Older Adults and Their Attitudes toward Computer Use," Current Gerontology and Geriatrics Research, vol. 2015, Article ID 849308, 7 pages, 2015. https://doi.org/10.1155/2015/849308

34. Ghaffari F, Navabi N, Gannat Alipoor Z. Older adults\&rsquo; attitudes and barriers toward the use of mobile phones. Clin Interv Aging. 2016;Volume 11:1371-8. doi: 10.2147/CIA.S112893

35. Wandke $H$, Sengpiel $M$, Sönksen $M$. Myths about older people's use of information and communication technology. Gerontology. 2012;58(6):564-70. doi: 10.1159/000339104 


\section{Anexos}

\section{A I - Questionário}

\section{CONSENTIMENTO INFORMADO}

$\mathrm{Eu}$

ACEITO, por livre

vontade, participar no preenchimento de um questionário, envolvido no projeto de investigação "Experiências e expetativas de pessoas idosas sobre as TIC (tecnologias de informação e comunicação) e sua perceção do estado de saúde".

Este projeto, do qual é investigadora principal a aluna Joana Daniela Gomes da Cunha, que constitui a sua Tese de Mestrado de Medicina, da FCS-UBI, é orientado pela Prof ${ }^{a}$ Rosa Marina Afonso, e no qual colaboram ainda os Prof.s Paulo Duarte e José Martinez de Oliveira, tem como objetivos: avaliar a interação da população idosa com a comunicação informática (experiência vivida e principais limitações) e definir um equipamento considerado "o ideal", de forma a facilitar a utilização das TIC (tecnologias de informação e comunicação).

Sei que este trabalho não tem financiamento, nem os investigadores qualquer retorno financeiro, direto ou indireto.

Tomei conhecimento, que a minha participação no projeto não acarreta nenhum benefício, nem riscos associados, sendo que apenas os responsáveis pelo trabalho terão acesso às respostas por mim facultadas, e que os dados das minhas respostas serão tratados de forma anónima. É para mim também claro que posso não participar e que esta vontade de não colaborar não implica qualquer perda de direitos.

Data:

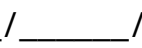

Assinatura: 


\section{QUESTIONÁRIO}

Assinale a sua resposta sobre o número que the corresponde com $\otimes$

\section{Perceção do estado de saúde}

1.1. De forma geral como avalia a sua saúde?
5) excelente
4) muito boa
3) boa
2) aceitável
1) má

1.2. Como é a sua visão (com óculos se usar)?
5) excelente
4) muito boa
3) boa
2) aceitável
1) má

1.3. Como é a sua audição (com aparelho se usar)?
5) excelente
4) muito boa
3) boa
2) aceitável
1) má

1.4. Como é o seu manuseamento (coordenação de mãos)?

5) excelente
4) muito bom
3) bom
2) aceitável
1) mau

1.5. Como está a sua memória (capacidade de recordar informações)?
5) excelente
4) muito boa
3) boa
2) aceitável
1) má 
1.6. Como é a sua autonomia (capacidade de realizar atividades sem ajuda)?

5) excelente

4) muito boa

3) boa

2) aceitável

1) má

\section{Contacto com as tecnologias:}

(Selecione a resposta correta)

\begin{tabular}{|c|c|c|c|c|c|}
\hline \multicolumn{6}{|l|}{ 2.1) Telemóvel } \\
\hline 2.1.1 Sabe o que é? & Sim & Não & \multicolumn{3}{|c|}{ Se respondeu Não passar para a próxima tabela } \\
\hline $\begin{array}{l}\text { 2.1.2 Já alguma vez } \\
\text { utilizou? }\end{array}$ & Sim & Não & \multicolumn{3}{|c|}{ Se respondeu Não passar para a próxima tabela } \\
\hline $\begin{array}{l}\text { 2.1.3 Continua a usá- } \\
\text { lo? }\end{array}$ & Nunca & Raramente & Ocasionalmente & Frequentemente & Sempre \\
\hline $\begin{array}{l}\text { 2.1.4 Como avalia essa } \\
\text { experiência? }\end{array}$ & Excelente & Muito boa & Boa & Aceitável & Má \\
\hline $\begin{array}{l}\text { 2.1.5 Se já não usa o } \\
\text { telemóvel, } \\
\text { porque } \\
\text { deixou? }\end{array}$ & & & & & \\
\hline
\end{tabular}

\section{2) Smartphone}

\begin{tabular}{lllllll}
\hline 2.2.1 & Sabe o que é? & Sim & Não & \multicolumn{2}{l}{ Se respondeu Não passar para a próxima tabela } \\
2.2.2 & $\begin{array}{l}\text { Já alguma vez } \\
\text { utilizou? }\end{array}$ & Sim & Não & Se respondeu Não passar para a próxima tabela \\
$\begin{array}{l}\text { 2.2.3 Continua a usá- } \\
\text { lo? }\end{array}$ & Nunca & Raramente & Ocasionalmente & Frequentemente & Sempre \\
$\begin{array}{l}\text { 2.2.4 Como avalia essa } \\
\text { experiência? }\end{array}$ & Excelente & Muito boa & Boa & Aceitável & Má \\
$\begin{array}{l}\text { 2.2.5 je já não usa o } \\
\text { smartphone, } \\
\text { porque } \\
\text { deixou? }\end{array}$ & & & & & \\
\hline
\end{tabular}




\begin{tabular}{|c|c|c|c|c|c|}
\hline \multicolumn{6}{|l|}{ 2.3) Tablet } \\
\hline 2.3.1 Sabe o que é? & Sim & Não & \multicolumn{3}{|c|}{ Se respondeu Não passar para a próxima tabela } \\
\hline $\begin{array}{l}\text { 2.3.2 Já alguma vez } \\
\text { utilizou? }\end{array}$ & Sim & Não & \multicolumn{3}{|c|}{ Se respondeu Não passar para a próxima tabela } \\
\hline $\begin{array}{l}\text { 2.3.3 Continua a usá- } \\
\text { lo? }\end{array}$ & Nunca & Raramente & Ocasionalmente & Frequentemente & Sempre \\
\hline $\begin{array}{l}\text { 2.3.4 Como avalia essa } \\
\text { experiência? }\end{array}$ & Excelente & Muito boa & Boa & Aceitável & Má \\
\hline $\begin{array}{cl}\text { 2.3.5 Se já não usa o } \\
\text { tablet, porque } \\
\text { o deixou? }\end{array}$ & & & & & \\
\hline
\end{tabular}

\begin{tabular}{llllll}
\hline 2.4) Computador & & & & & \\
\hline 2.4 .1 & Sabe o que é? & Sim & Não & Se respondeu Não passar para a próxima tabela \\
2.4 .2 & $\begin{array}{l}\text { Já alguma vez } \\
\text { utilizou? }\end{array}$ & Sim & Não & Se respondeu Não passar para a próxima tabela \\
$\begin{array}{l}\text { 2.4.3 Continua a usá- } \\
\text { lo? }\end{array}$ & Nunca & Raramente & Ocasionalmente & Frequentemente & Sempre \\
$\begin{array}{l}\text { 2.4.4 Como avalia essa } \\
\text { experiência? }\end{array}$ & Excelente & Muito boa & Boa & Aceitável & Má \\
$\begin{array}{l}\text { 2.4.5 já não usa o } \\
\text { computador } \\
\text { porque } \\
\text { deixou? }\end{array}$ & & & & & \\
\hline
\end{tabular}


Experiências de pessoas idosas institucionalizadas sobre as Tecnologias de Informação e Comunicação (TIC) e sua perceção do estado de saúde

2.5. Com que finalidade utiliza estes equipamentos?

\begin{tabular}{|c|c|c|c|c|c|c|}
\hline & \multirow{2}{*}{$\begin{array}{l}\text { Não Utiliza } \\
\text { (para...) }\end{array}$} & \multicolumn{4}{|c|}{ Utiliza } & \multirow{2}{*}{$\begin{array}{l}\text { Que equipamento } \\
\text { utiliza } \\
\text { (Inserir } \mathrm{n}^{\circ} \text { das } \\
\text { tabelas anteriores) }\end{array}$} \\
\hline & & Raramente & Ocasionalmente & Frequentemente & Sempre & \\
\hline \multicolumn{7}{|l|}{$\begin{array}{l}\text { Aceder à } \\
\text { Internet }\end{array}$} \\
\hline \multicolumn{7}{|l|}{$\begin{array}{l}\text { Conversar com } \\
\text { a família }\end{array}$} \\
\hline \multicolumn{7}{|l|}{$\begin{array}{l}\text { Falar com } \\
\text { amigos }\end{array}$} \\
\hline \multicolumn{7}{|l|}{$\begin{array}{l}\text { Encontrar } \\
\text { antigos amigos }\end{array}$} \\
\hline \multicolumn{7}{|l|}{$\begin{array}{l}\text { Fazer novas } \\
\text { amizades }\end{array}$} \\
\hline \multicolumn{7}{|l|}{$\begin{array}{l}\text { Utilizar as } \\
\text { redes sociais }\end{array}$} \\
\hline \multicolumn{7}{|l|}{ Ler notícias } \\
\hline \multicolumn{7}{|l|}{ Fazer pesquisas } \\
\hline \multicolumn{7}{|l|}{$\begin{array}{l}\text { Procurar } \\
\text { informações } \\
\text { sobre saúde }\end{array}$} \\
\hline \multicolumn{7}{|l|}{$\begin{array}{l}\text { Utilizar } \\
\text { aplicações de } \\
\text { saúde }\end{array}$} \\
\hline \multicolumn{7}{|l|}{$\begin{array}{l}\text { Realizar } \\
\text { compras online }\end{array}$} \\
\hline \multicolumn{7}{|l|}{ Enviar e-mails } \\
\hline \multicolumn{7}{|l|}{ Ouvir música } \\
\hline \multicolumn{7}{|l|}{ Escrever textos } \\
\hline \multicolumn{7}{|l|}{ Ver vídeos } \\
\hline \multicolumn{7}{|l|}{ Assistir a filmes } \\
\hline Outros & & & & & & \\
\hline
\end{tabular}

2.6. Começou a usar os equipamentos referidos por iniciativa própria?

Sim__ Não

2.7. Quem o ensinou/incentivou a utilizá-los? 
2.8. Tem algum receio na utilização destes equipamentos?

$\operatorname{Sim}$

Não

2.9. Tem dificuldades na utilização do equipamento?

Sim

Não

2.10. Quais as principais dificuldades?

2.10.1 Letra pequena

2.10.2 Teclas muito próximas

2.10.3 Limitação física

2.10.4 Trabalhar com o rato

2.10.5 Encontrar informações

2.10.6 Pouco tempo para ler/escolher o que quer

2.10.7 Outras

2.11.Tem a quem recorrer se precisar de ajuda?

Sim__ Não_

2.11.A Se sim, quem?

\section{Envolvimento desejável:}

3.1.Gostaria de ter formação/aulas sobre a utilização destes equipamentos? $\operatorname{Sim}$ Não

3.2. Considera importante o uso destes equipamentos?

Sim__ Não_

3.3. Tem interesse na utilização das novas tecnologias?

Sim Não

3.4. Como acredita que seria mais fácil utilizar os equipamentos? Sem necessidade de teclados Sem necessidade de monitores clássicos

Comandando apenas por gestos

__ Comandando apenas com a voz (de mando) 
3.5 Tem medo de "navegar" na Internet?

Sim__ Não

3.5.1 O que mais o assusta?

4. Dados Pessoais e sociodemográficos

4.1.Idade:

4.2.Género:

4.3. Meio de origem: Rural Urbano

4.4.Profissão:

4.5. Escolaridade:

4.6. Agregado Familiar: Filhos Netos Irmãos

4.6.1. Outros:

4.6.2. Onde estão?

5. Informação clínica (a recolher a partir de processo do participante)

5.1.Diagnósticos:

\subsection{Medicação:}




\title{
A II - Parecer da Comissão de Ética da Faculdade de Ciências da \\ Saúde
}

Parecer relativo ao processo n. ${ }^{\circ}$ CE-UBI-Pj-2018-o 36

Na sua reunião de 10 de jullho de 2018 , a Comissão de Ética apreciou a documentação cientifica submetida referente ao pedido de parecer do projeto "Experiências e expectativas de pessoas idosas em relação às TIC (tecnologias de informação $e$ comumicação) e perceção do seu estado de saúde", da proponente Joana Damiela Gomes da Cunha, a que atribuiu o código n-0 CE-UBI-PJ-2018-036.

Na sua análise não identificou matéria que ofenda os princípios éticos e morais sendo de parecer que o estudo em causa pode ser aprovado.

Covilhã e UBI, 18 de julho de 2018

\author{
o Vice-Presidente da Comissão de Ética \\ Professor Doutor José António Campelo de Sousa Amaral
}

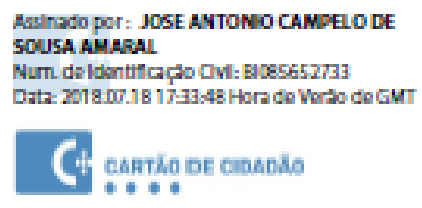




\section{A III - E-mail direcionado a algumas Instituições}

Exmo. Sr.

Venho, por este meio, solicitar a participação dos utentes da , para participarem no preenchimento de um questionário sobre as expetativas dos idosos institucionalizados em relação às TIC (tecnologias de informação e comunicação) e sua perceção do estado de saúde. Este questionário destina-se à elaboração de uma dissertação do Mestrado Integrado em Medicina, da Universidade da Beira Interior, intitulada "Experiências e expectativas de pessoas idosas em relação às TIC (tecnologias de informação e comunicação) e perceção do seu estado de saúde", que será orientada pela Professora Rosa Marina Lopes Brás Martins Afonso e coorientada pelo Dr. José Martinez de Oliveira e pelo Professor Paulo Alexandre Oliveira Duarte, da Universidade da Beira Interior.

Como consequência dos desenvolvimentos científicos e técnicos, das alterações económicas e do aumento da consciencialização da importância conferida à educação, à higiene e à saúde pública, tem-se assistido a várias transformações demográficas, que se traduzem por uma população cada vez mais envelhecida. Porém, nem sempre este envelhecimento é acompanhado de qualidade de vida, sendo comum o isolamento social, a depressão e solidão dos mais velhos, considerados importantes preditores de morte prematura. A par disto, é notório que as Tecnologias de Informação e Comunicação (TIC) se têm vindo a instalar no diaa-dia de todos, promovendo a construção de redes sociais que facilitam a comunicação, fomentam ferramentas de aprendizagem e minimizam as lacunas que a distância física impõe.

Assim, é pertinente abordar esta temática, para melhor avaliar as experiências e expectativas de pessoas idosas em relação às TIC e o possível impacto que isso possa vir a ter na sua perceção do estado de saúde.

Caso a vossa instituição aceite colaborar neste estudo, iremos solicitar a aplicação do questionário referido. 0 estudo foi aprovado pela Comissão de Ética da UBI. Os resultados dos questionários serão anónimos e confidenciais.

Agradecemos a sua atenção e disponibilidade.

Com os melhores cumprimentos,

A estudante,

Joana Cunha 
Experiências de pessoas idosas institucionalizadas sobre as Tecnologias de Informação e Comunicação (TIC) e sua perceção do estado de saúde 